PONTIFÍCIA UNIVERSIDADE CATÓLICA DO RIO DE JANEIRO

\begin{abstract}
A recessão brasileira e seu impacto nos investimentos em Responsabilidade Social Empresarial
\end{abstract}

Carolina Góes Lacerda

Trabalho de Conclusão de Curso

Centro de Ciências socials - CCS

DEPARTAMENTO dE AdMINISTRAÇÃO

Graduação em Administração de Empresas 
Carolina Góes Lacerda

\title{
A recessão brasileira e seu impacto nos investimentos em Responsabilidade Social Empresarial
}

\author{
Trabalho de Conclusão de Curso
}

Trabalho de Conclusão de Curso, apresentado ao programa de graduação em Administração da PUC-Rio como requisito parcial para a obtenção do título de graduação em Administração.

Orientador: Martim Francisco de Oliveira e Silva 


\section{Agradecimentos}

Agradeço primeiramente aos meus pais e avós pelos contínuos investimentos e oportunidades de ensino a mim concedidas, bem como todo apoio e amor, que foram essenciais. Ao Guilherme, toda minha gratidão e amor pelo apoio, paciência e generosidade e ao meu orientador, Martim, pelo auxílio e direcionamento durante todo o processo de desenvolvimento deste trabalho. 


\section{Resumo}

Góes Lacerda, Carolina. A recessão brasileira e seu impacto nos investimentos em Responsabilidade Social Empresarial. Rio de Janeiro, 2019. 40p. Trabalho de Conclusão de Curso - Departamento de Administração. Pontifícia Universidade Católica do Rio de Janeiro.

Os investidores e empresas têm dado mais atenção a Responsabilidade Social Empresarial (RSE), devido ao potencial de obtenção de retornos econômicos de longo prazo. Tendo em vista a recessão econômica que o Brasil enfrentou entre 2014 e 2016, o objetivo desta pesquisa foi analisar o seu impacto nos investimentos em RSE. Foi feita uma análise quantitativa, com base na análise de Relatórios de Sustentabilidade e Demonstrações financeiras de 10 empresas participantes do ISE (Índice de Sustentabilidade Empresarial), associando seus resultados à duas teorias: da Organização Industrial e da Visão Baseada em Recursos. Os resultados indicaram que a maioria das empresas tendeu a reduzir seus investimentos em RSE durante a recessão, ainda que estes fossem relevantes para suas estratégias empresariais.

Palavras- chave

Responsabilidade Social Empresarial, RSE, recessão, investimentos, Brasil 


\section{Abstract}

Góes Lacerda, Carolina. The Brazilian recession and its impact on Corporate Social Responsibility investments. Rio de Janeiro, 2019. 40p. Trabalho de Conclusão de Curso - Departamento de Administração. Pontifícia Universidade Católica do Rio de Janeiro.

Recently investors and organizations have put Corporate Social Responsibility (CSR) in a limelight, due to its capability of enabling long-term economic returns. Since Brazil has faced an economic recession from 2014 to 2016 this research's objective is to analyse its impact on local companies CSR investments. A quantitative analysis was conducted, based in Sustainability Reports and Financial Statements of 10 companies that are a part of ISE (Business Sustainability Index). After that two theories were used: Industrial Organization and the Resource-Based View. The results showed that most companies had a tendency of reducing Corporate Social Responsibility investments during the recession, although they were relevant to their business strategies.

Keywords

Corporate Social Responsibility, CSR, recession, investments, Brazil 


\section{Sumário}

1. Introdução 1

1.1. Contexto e problema de estudo 1

1.2. Objetivo do estudo 3

1.3. Objetivo intermediários 3

1.4. Delimitação e foco do estudo 3

1.5. Relevância 3

2. Referencial Teórico 5

2.1. Responsabilidade Social Empresarial (RSE) 5

2.2. Investimento socialmente responsável 7

2.3. Gestão estratégica e RSE 9

2.3.1. Organização Industrial e Visão Baseada em Recursos (VBR) 10

$\begin{array}{ll}\text { 2.3.2. Ambiente externo e recessão } & 10\end{array}$

3. Metodologia 12

3.1. Tipo de pesquisa 12

3.2. Limitações do Método 13

3.3. Amostra 13

3.4. Fontes de dados 15

3.5. Tratamento e Análise dos dados 16

4. Apresentação e análise dos resultados 18

4.1. Análise para o conjunto de todas as empresas 18

4.2. Análise para o agrupamento por Grau de Governança na B3 19

4.3. Análise para o agrupamento por utilização de insumos da natureza 21

4.4. Análise individual de empresas 23

5. Conclusões 28 
6. Referências Bibliográficas

Anexo 


\section{Lista de Figuras}

Figura 1: Resumo de benefícios da RSE 


\section{Lista de Tabelas}

Tabela 1: Mediana Coeficiente de Pearson - Agrupamento Geral

Tabela 2: Mediana Coeficiente de Pearson -

Agrupamento Grau de Governança na B3

Tabela 3: Coeficiente de correlação de Pearson -

Agrupamento Utilização de insumos da natureza

Tabela 4: Coeficiente de correlação - EDP

Tabela 5: Coeficiente de correlação - Fibria

Tabela 6: Coeficiente de correlação - Engie

Tabela 7: Coeficiente de correlação - CCR

Tabela 8: Coeficiente de correlação - WEG 


\section{Introdução}

\subsection{Contexto e problema de estudo}

O conceito de Responsabilidade Social Empresarial (RSE), segundo Dahlsrud (2008), está presente nas organizações, uma vez que estas são impactadas por questões sociais, econômicas e relacionadas ao meio ambiente, e também sofrem influência de seus stakeholders $^{1}$, como o governo, clientes e proprietários. No entanto, em um nível operacional este conceito pode não ser tão facilmente percebido (DAHLSRUD, 2008).

Segundo uma pesquisa realizada pelo Boston Consulting Group (BCG) em 2017, atualmente três fatores contribuem para que as empresas voltem sua atenção para os fatores ambientais, econômicos e sociais (DOUGLAS et al. 2017).

Primeiramente, há uma pressão crescente por parte dos stakeholders para que as empresas tenham uma postura mais ativa em relação a problemas críticos, como inclusão econômica e mudança climática.

Em segundo lugar, os investidores estão cada vez mais interessados nas práticas sociais e ambientais, uma vez que a performance da empresa nestas áreas afeta os seus resultados financeiros de longo prazo.

Em terceiro lugar, estão sendo desenvolvidos padrões para que questões ambientais, sociais e de governança corporativa sejam financeiramente mensuradas pela indústria. Além disso, os dados empresariais de tais áreas estão se tornando mais accessíveis e confiáveis, o que aumenta a transparência e permite maior controle por parte dos seus stakeholders.

Neste contexto, instrumentos de gestão da RSE tornam-se parte integrante dos objetivos e estratégias da organização, para que seja planejada e executada uma estratégia organizacional de sucesso.

Segundo Porter (1992), as estratégias de alocação de recursos internos das empresas são influenciadas pela percepção desta de como os investidores avaliam as empresas. Ao mesmo tempo, para avaliar o valor das empresas, os investidores levam em consideração a forma como as empresas são administradas e como alocam seus recursos. Esta associação

${ }^{1}$ Pessoas ou organizações que podem afetar ou serem afetadas pelas ações de uma organização, como: fornecedores, concorrentes, consumidores, mídia, instituições financeiras, Governos (e suas agências), funcionários e acionistas. SOBRAL, F; PECI, A. Administração: teoria e prática no contexto brasileiro - São Paulo: Pearson Prentice Hall, 2012. 
entre investimentos internos e externos cria um ciclo que reforça certos tipos de investimentos e demonstra que existe uma relação mais forte entre a gestão estratégica das empresas, seu valor e seu comportamento empresarial.

RSE tende a ser altamente associada a boas práticas de governança corporativa (OECD, 2004, apud KARAIBRAHIMOĞLU, 2010) e, se realizada de forma transparente, pode reduzir a assimetria de informações entre investidores e gestores, o que por sua vez, pode gerar um aumento da confiança do investidor externo na empresa (MILANO FILHO, 2008).

Além disso, empresas sustentáveis podem gerar maior retorno aos acionistas no longo prazo, uma vez que tendem a estar mais preparadas para enfrentar riscos econômicos, sociais e ambientais (MILANI FILHO, 2008).

Nesse sentido, uma pesquisa do BCG de 2017 mostra que em 2016, os ativos globais na área de investimentos socialmente responsáveis chegaram a quase 23 trilhões de dólares, representando um aumento de $27,7 \%$ em relação ao ano 2014 , época em que tais ativos somavam 18 trilhões de dólares (DOUGLAS et al., 2017).

Como resposta a estas mudanças no ambiente de negócios, surgiram em vários países índices de sustentabilidade. Taís índices visam oferecer aos investidores uma opção de carteira composta por ações de empresas que apresentam reconhecido comprometimento com a responsabilidade social e a sustentabilidade empresarial (MILANI FILHO, 2008). São exemplos destes: o Índice Dow Jones de Sustentabilidade (IDJS), nos Estados Unidos e o Índice de Sustentabilidade Empresarial (ISE), no Brasil.

O ISE teve uma valorização de 185,01\% de 2005 a 2017, superior à valorização do índice do lbovespa no período, que foi de 113,72\% (DECLOEDT, 2017). Tal resultado sugere que os investidores estão se tornando mais preocupados com RSE e com retornos de longo prazo, mesmo diante de eventos como a crise econômica mundial que teve início em 2007 (FMI, 2012) e a recessão econômica enfrentada pelo Brasil desde meados 2014 até final de 2016 (CODACE, 2017).

Historicamente, as práticas de RSE receberam ainda mais atenção devido a colapsos de grandes empresas e escândalos financeiros (KARAIBRAHIMOĞLU, 2010), como a falência da Enron, em 2001, e da Lehman Brothers, em 2008, devido a fraudes contábeis (GARA, 2015).

Assim, estudos que relacionem recessões econômicas com investimentos em RSE tendem a ser relevantes, especialmente para o Brasil, que enfrentou uma recessão econômica entre 2014 e 2016, uma vez que tais investimentos poderiam (ou deveriam) ser preservados, principalmente por empresas participantes de índices de sustentabilidade, como o ISE. 
Por outro lado, é possível que, dependendo de circunstâncias específicas das empresas, como a indústria em que ela atua ou mesmo de suas escolhas individuais, os investimentos em RSE, mesmo de empresas participantes do ISE possam ser afetados de maneira relevante por circunstâncias econômicas específicas de seu ambiente mais geral, como uma retração semelhante à experimentada pelo país entre 2014 e 2016.

Por estas razões, a pesquisa buscou investigar o relacionamento entre a recessão econômica brasileira e os investimentos das empresas em projetos de Responsabilidade Social, respondendo à pergunta:

- Há relação entre os investimentos em RSE e a variação do PIB no Brasil?

\subsection{Objetivo do estudo}

O objetivo do estudo foi identificar a existência de relacionamento entre desempenho econômico nacional e os investimentos em RSE de empresas brasileiras entre os anos de 2010 e 2017.

\subsection{Objetivo intermediários}

Para alcançar os objetivos do estudo, foi necessário atingir os seguintes objetivos intermediários:

- Selecionar empresas com boas práticas de RSE.

- Analisar os investimentos das empresas em RSE e compará-los com seus investimentos totais, receitas e variações do PIB no país.

\subsection{Delimitação e foco do estudo}

O estudo analisou dados financeiros das empresas da amostra desde o ano de 2010 até 2017. Foram analisadas 10 empresas dentre as 30 participantes do ISE no ano de 2018, que, por fazerem parte de um índice de sustentabilidade, deveriam considerar investimentos em RSE como elemento de grande importância estratégica.

\subsection{Relevância}

A pesquisa é relevante principalmente para empresas, pesquisadores e a sociedade em geral.

Para as empresas, ela contribui para conscientizá-las da necessidade e dos benefícios de uma política de RSE, como forma de atender de maneira mais efetiva aos interesses de seus principais stakeholders. 
Para os pesquisadores, contribui para a discussão que envolve a relação entre RSE, ciclos econômicos e a atuação das empresas.

Finalmente, para a sociedade em geral, possibilita que as pessoas tenham mais informações sobre o comprometimento com RSE das empresas que nela atuam. 


\section{Referencial Teórico}

\subsection{Responsabilidade Social Empresarial (RSE)}

Para Dahlsrud (2008), as definições de RSE estão categorizadas em cinco categorias e através delas o conceito de RSE pode ser compreendido. As categorias por ele percebidas são: ambiental (o ambiente natural), social (relação entre empresa e sociedade), econômica (aspectos socioeconômicos ou financeiros), do stakeholder (interação com stakeholders) e da voluntariedade (ações não descritas na lei).

O ambiente de negócios tem sofrido mudanças e as organizações são vistas como parte importante da sociedade. Por este motivo, Sunder (1997, apud KARAIBRAHIMOĞLU, 2010) propõe que RSE seja vista como um conjunto de contratos entre a empresa e seus stakeholders - funcionários, consumidores, gestores, investidores, fornecedores, auditores, etc. Esta definição destaca a responsabilidade social atribuída às empresas nos dias atuais.

Já para o Instituto Ethos, RSE diz respeito à tentativa, pelas empresas, de integrar seus interesses e de seus stakeholders, levando em consideração três dimensões, também conhecidas como Triple Bottom Line: Econômica, Social e Ambiental (INSTITUTO ETHOS, 2006, apud MILANI FILHO, 2008). Nesta pesquisa a definição do Instituto Ethos foi empregada como conceito de RSE.

Um dos principais motivos de RSE ser tão discutida atualmente diz respeito à sua associação aos padrões de boa governança corporativa (OECD, 2004, apud KARAIBRAHIMOĞLU, 2010). O conceito de governança corporativa é entendido como um conjunto de mecanismos de incentivo e controle, tanto internos, como externos, que têm como objetivo minimizar os custos decorrentes de problema de agência entre alguns dos stakeholders de uma empresa, notadamente os acionistas e gestores (JENSEN; MECKLING, 1976, apud SAITO; SILVEIRA, 2008). Milani Filho (2008) destaca ainda que instrumentos de governança eficazes aumentam a confiança do investidor externo, uma vez que podem diminuir a assimetria de informações entre investidores e gestores.

Boas práticas de RSE também podem ter um efeito positivo no comportamento do consumidor (MOHR et al. 2001, apud KARAIBRAHIMOĞLU, 2010). Recentemente os stakeholders têm se mostrado bastante interessados em projetos de RSE que as empresas realizam, o que significa que as empresas também são avaliadas em relação à sua preocupação com a sociedade com a qual opera (KARAIBRAHIMOĞLU, 2010). 
Karaibrahimoğlu (2010) destaca ainda que a natureza das empresas é maximizar lucros e seu engajamento em projetos de RSE pode permitir elevar sua sustentabilidade ao garantir o lucro no longo prazo, uma vez que empresas sustentáveis estão mais preparadas para enfrentar riscos econômicos, sociais e ambientais (MILANI FILHO, 2008).

É importante ressaltar também os benefícios de diferentes tipos de ações de RSE, como as ações voltadas para o público interno (como treinamentos e benefícios) são investimentos no capital humano, o que pode tornar a empresa mais competitiva. Ações voltadas para gerar um melhor relacionamento com stakeholders externos também podem gerar melhores condições de compra e pagamento dos insumos produtivos, o que também melhora a competitividade da empresa.

Soma-se a essas ações citadas o cumprimento de obrigações legais, que evita que a empresa e seus gestores sejam penalizados. O investimento em equipamentos de proteção ambiental também evita multas e processos jurídicos advindos de danos causados ao meio ambiente. Todas as atitudes destacadas estão diretamente relacionadas com a sustentabilidade de uma empresa e podem contribuir para melhores resultados futuros, bem como aumento do valor de mercado da organização (MILANO FILHI, 2008).

Finalmente, os projetos de RSE podem ajudar as empresas a se diferenciarem de outras organizações, o que pode ser percebido positivamente pelos stakeholders (MORSING; SCHULTZ, 2006, apud KARAIBRAHIMOĞLU, 2010).

A Figura 1 identifica um resumo dos benefícios das boas práticas de RSE. 
Figura 1: Resumo de benefícios da RSE

\begin{tabular}{|c|c|}
\hline Benefícios & Autores \\
\hline Associado a boa governança corporativa & OECD, 2004, apud KARAIBRAHIMOGLU, 2010 \\
\hline Maior confiança do investidor exerno & MILANI FILHO, 2008 \\
\hline Efeito positivo no comportamento do consumidor & MOHR et al. 2001, apud KARAIBRAHIMOGLU, 2010 \\
\hline $\begin{array}{l}\text { Torna as empresas mais aptas a enfrentarem riscos } \\
\text { econômicos, sociais e ambientais }\end{array}$ & MILANI FILHO, 2008 \\
\hline Possibilita resultado econômico de longo prazo & KARAIBRAHIMOGLU, 2010 \\
\hline Torna a empresa mais competitiva & MILANI FILHO, 2008 \\
\hline $\begin{array}{c}\text { Evita que a empresa seja penalizada pelo não } \\
\text { cumprimento de ações legais ou por danos causados ao } \\
\text { meio ambiente }\end{array}$ & MILANI FILHO, 2008 \\
\hline Promove diferenciação empresarial & $\begin{array}{c}\text { MORSING; SCHULTZ, 2006, apud KARAIBRAHIMOGLU, } \\
2010\end{array}$ \\
\hline
\end{tabular}

Fonte: Elaborada pela Autora.

\subsection{Investimento socialmente responsável}

A discussão acerca da importância da RSE teve seu início no meio acadêmico e empresarial na década de 1950, nos Estados Unidos. No entanto, o tema só se tornou mais conhecido em 1960, também nos Estados Unidos, devido a transformações sociais que fizeram emergir diversos problemas socio econômicos (CARVALHO; BENEDICTO, 2018).

$\mathrm{Na}$ década de 70 surgiu a preocupação de como e quando a empresa deveria responder às suas obrigações sociais. Também nesta década a demonstração das ações organizacionais para a sociedade tornou-se muito importante, sendo a França o primeiro país a exigir que as empresas fizessem balanços periódicos em relação ao seu desempenho social relacionado à mão de obra e suas condições de trabalho (OLIVEIRA, 2000, apud CARVALHO; BENEDICTO, 2018).

Já na década de 80 , aumentaram-se as pressões sobre as empresas em relação à alguns aspectos econômicos, o que criou um cenário ainda mais propício para a difusão da RSE. Nos países em via de democratização política, este tema passou a ser associado com 
ética organizacional e qualidade de vida no trabalho (BENEDICTO, 2002, apud CARVALHO; BENEDICTO, 2018).

Este é o caso do Brasil, que na década de 80 vivia o fim da ditadura militar, a crescente globalização econômica e financeira, a reestruturação do trabalho e mudanças no papel social do Estado. Tais fatos geraram um cenário paradoxal, uma vez que houve um aumento na pobreza da população, bem como a acumulação de riquezas pelas empresas. Tal conjuntura fez com que empresários começassem a investir em ações sociais (SARTORE, 2012).

Em 1995, no Brasil, surgiu o GIFE - Grupo de Institutos Fundações e Empresas -, que implementou a ideia de investimento social privado, que é definindo como o direcionamento de recursos privados, tanto de pessoas físicas, como jurídicas, para projetos e ações sociais, sem a necessidade de parcerias com o Terceiro Setor. A iniciativa se diferia de práticas assistencialistas, pois esperava-se que o investidor se envolvesse com as ações e resultados proporcionados à comunidade e existisse um comprometimento com 0 monitoramento e avaliação dos projetos (GIFE, 2002, apud MILANI FILHO, 2008).

Em 2000, a Bolsa de Mercados e Futuros - BM\&FBovespa - criou segmentos de listagem que prezam por regras de governança corporativa diferenciadas. De acordo com a BM\&FBovespa (2019b), a listagem de empresas em relação ao seu grau de governança foi criada para ajudar a desenvolver o mercado de capitais brasileiro ao instituir regras de governança que buscavam melhorar a avaliação das empresas que, voluntariamente, decidissem participar de algum dos segmentos de listagem.

O segmento de listagem que diz respeito ao mais elevado nível de governança corporativa é o Novo Mercado e fazem parte deste segmento empresas que adotam, voluntariamente, ações de transparência e governança que vão além do que é previsto na legislação (BM\&FBOVESPA, 2019a).

Em 2005 foi criado, pela Bovespa - Bolsa de Valores de São Paulo - o ISE - Índice de Sustentabilidade Empresarial, que considerava que empresas sustentáveis geram valor para o acionista no longo prazo, uma vez que, teoricamente, estão mais bem preparadas para enfrentar riscos econômicos, sociais e ambientais (MILANO FILHO, 2008).

O ISE é uma ferramenta usada para comparar o desempenho das empresas listadas na B3 sob o aspecto da sustentabilidade corporativa, que tem como base a eficiência econômica, equilíbrio ambiental, justiça social e governança corporativa. Tal índice busca criar um ambiente de investimento compatível com as demandas de desenvolvimento sustentável e incentivar as empresas a serem eticamente responsáveis (BM\&FBOVESPA, 2018). 


\subsection{Gestão estratégica e RSE}

Para Porter (1996), estratégia diz respeito à criação de uma posição ímpar e valiosa adotada pela empresa como um todo e que envolve um conjunto de ações que a empresa realiza para se diferenciar da competição. Entre estas ações, a alocação e natureza dos investimentos em distintas áreas organizacionais fazem parte da estratégia das empresas.

Porter (1996) cita ainda que a estratégia de uma empresa é a base para que uma vantagem competitiva sustentável seja alcançada. Para que seja criada uma vantagem competitiva sustentável se tornam necessários fatores como: a estratégia empresarial deve oferecer uma posição competitiva única para toda a empresa; as atividades empresariais devem ser alinhadas a esta estratégia; as atividades empresariais devem ser adequadas entre si. É preciso fazer muitas coisas da forma correta e integrá-las entre si; existem tradeoffs e escolhas claras em comparação com os concorrentes.

Segundo Van Marrewijk (2003, apud DAHLSRUD, 2008) para que uma estratégia de RSE seja bem-sucedida é necessário que ela seja adequada ao contexto de cada negócio. Seguindo este caminho, Carriço e Kirshner (2010) destacam que o caminho perseguido pelas empresas é criar uma estratégia de RSE que esteja alinhada com seus objetivos empresariais.

Carriço e Kirshner (2010) também destacam que RSE tem sido considerada uma parte da gestão estratégia da empresa e para isso se faz necessário o uso de instrumentos de gestão próprios para análise empresarial de investimentos econômicos (PORTER; KRAMER, 2006 apud CARRIÇO; KIRSHNER, 2010).

Reforçando a importância de instrumentos de gestão de RSE, Dahlsrud (2008) cita que novos stakeholders estão surgindo, bem como novas legislações sociais, o que gera novas expectativas em relação às empresas e altera a forma como as dimensões social, ambiental e econômica devem ser balanceadas para otimizar as decisões. Tais mudanças fazem com que seja importante a utilização de instrumentos de gestão de RSE para que se estabeleça uma estratégia de negócios de sucesso.

Além disso, uma empresa deve, ao investir em projetos sociais, legitimar seus gastos sociais, utilizando uma abordagem de custo-efetividade. Isto é feito ao se comparar os custos unitários obtidos neste tipo de projeto com os objetivos finais e com seus níveis de eficácia. Ao se utilizar esta abordagem a probabilidade de erro de se optar por um projeto social se torna muito menor (RODRIGUES, 2010, apud CARRIÇO; KIRSHNER, 2010).

Ainda em relação à legitimidade do gasto social, as empresas têm que verificar se estão promovendo mudanças significativas e perenes, uma vez que sem esta verificação os investimentos sociais passam a ser um "tiro no escuro" ou, até pior, um gasto em publicidade disfarçado (CARRIÇO; KIRSHNER, 2010). 


\subsubsection{Organização Industrial e Visão Baseada em Recursos (VBR)}

Existem duas perspectivas dominantes do campo da pesquisa acadêmica em estratégia que são utilizadas para explicar o desempenho empresarial, sendo elas a visão da indústria e a visão da empresa (SILVA et al., 2012).

A visão da indústria baseada no campo econômico da teoria da Organização Industrial cita que o desempenho de uma empresa depende das características da indústria de qual faz parte (PORTER, 1981). Essa relação entre a empresa e as características de sua indústria forma o modelo estrutura-conduta-desempenho, que diz que a estrutura da indústria determina a conduta (comportamento) das empresas, cujas condutas, conjuntamente, determinam a performance coletiva das empresas daquela indústria. (BAIN, 1968; MASON, 1953; apud PORTER, 1981).

Já a visão da empresa deve ser analisada com base em sua posição individual competitiva favorável (AMIT; SCHOEMAKER, 1993; DIERICKX; COOL, 1989; PENROSE, 1959; PETERAF, 1993; WERNERFELT, 1984, apud SILVA et al., 2012). A Visão Baseada em Recursos (VBR), é uma teoria relacionada à perspectiva da visão da empresa que destaca uma maior importância das ações da própria empresa do que da estrutura da indústria no desempenho organizacional (AMIT; SCHOEMAKER, 1993; CONNER, 1991, apud SILVA et al., 2012).

Tal teoria diz que os atributos de uma empresa que são de difícil cópia pelos concorrentes são essenciais para se obter uma performance positiva e vantagem competitiva (CONNER, 1991).

\subsubsection{Ambiente externo e recessão}

O ambiente externo da empresa corresponde a todo elemento externo à organização que a afeta. Fazem parte do ambiente externo: elementos de ação indireta, características de mercado, análise da estrutura de mercado, análise da elasticidade-preço da demanda e análise dos elementos de ação direta (SOBRAL \& PECI, 2008).

No ambiente externo, para efeito desta pesquisa, se fez importante destacar os elementos de ação direta e indireta. Elementos de ação direta são todos os elementos que interagem de forma mais direta com a empresa, como seus stakeholders - clientes fornecedores, concorrentes e agências reguladoras (SOBRAL \& PECI, 2008).

Já os elementos de ação indireta, que não atuam diretamente sobre a empresa, são variáveis econômicas, político-legais, demográficas, socioculturais, ambientais e tecnológicas. Dentre as variáveis citadas, destaca-se a importância, para esta pesquisa, da 
variável econômica, que envolve fatores que influenciam economicamente o comportamento do mercado, de forma positiva ou negativa (SOBRAL \& PECI, 2013) e por extensão, às empresas. As variáveis socioculturais e ambientais também são de suma importância, uma vez que, juntamente com a variável econômica, dizem respeito às três dimensões de RSE.

O National Bureau of Economic Research (NBER) é uma organização americana privada, sem fins lucrativos e apartidária fundada em 1920 e tem como objetivo conduzir pesquisas econômicas e disseminá-las para acadêmicos, Governo e profissionais da área de negócios (NBER, 2019). Este define a recessão, que é um dos principais fatores da pesquisa em questão, como o declínio da atividade econômica em diversos setores econômicos e que pode durar de alguns meses até mais de um ano (NBER, 2010).

Esta pode ser percebida pela queda do Produto Interno Bruto (PIB), da renda familiar, dos lucros, do nível de investimento, bem como pelo aumento do desemprego e número de falências de empresas (NBER, 2010) e, de acordo com o Comitê de Datação de Ciclos Econômicos (CODACE) da Fundação Getúlio Vargas (FGV), o Brasil enfrentou uma recessão desde o segundo trimestre de 2014 até o quarto trimestre do ano de 2016 (CODACE, 2017).

Em um cenário de recessão, é presumido que empresas ajam mais conservadora e defensivamente e por este motivo, podem decidir não realizar projetos de RSE e, em decorrência, não atingir as expectativas de seus diferentes stakeholders (CHENEY et al., 1990, apud KARAIBRAHIMOĞLU, 2010).

No entanto, para enfrentar a recessão, as empresas deveriam focar em atender às necessidades da sociedade e projetos transparentes de RSE podem oferecer o suporte para que isso seja possível (WILSON, 2008, apud KARAIBRAHIMOĞLU, 2010).

Karaibrahimoğlu (2010) cita, então, um dilema criado, que diz respeito ao fato de uma recessão demandar mais investimentos em RSE, ao mesmo tempo que as empresas estão menos dispostas a realizá-los.

Njoroge (2009, apud KARAIBRAHIMOĞLU, 2010) cita que a recessão pode fazer com que as empresas paralisem, adiem ou cancelem projetos de cunho social.

Já Carriço e Kirshner (2010) destaca que, em períodos de incertezas, como em uma recessão, as empresas se preocupam em investir em processos de produção mais eficientes, com o objetivo de reduzir seus custos de produção. Em relação ao ISP, nestes períodos as empresas dão prioridade a dar continuidade a investimentos que estejam diretamente ligados à estratégia organizacional (CARRIÇO; KIRSHNER, 2010).

Finalmente, Carriço e Kirshner (2010) também citam que a manutenção de projetos sociais em épocas de recessão não teria um efeito negativo em empresas mais sólidas e destacam ainda que se feito de forma responsável ISP podem até compensar, através da percepção de valores intangíveis, humanitários e éticos, os investimentos realizados. 


\section{Metodologia}

\subsection{Tipo de pesquisa}

Uma pesquisa descritiva busca interpretar um fenômeno, sem modificá-lo (VIEIRA, 2002). Por este motivo a pesquisa em questão foi descritiva, uma vez que buscou interpretar a recessão, tendo em vista seu impacto nos investimentos em RSE.

Também foi uma pesquisa documental, pois foram investigados documentos a fim de se comparar a relação entre a variação do PIB e a variação dos investimentos em RSE (MANZATO, 2011).

Silva et al., 2012 citam que o ambiente empresarial é complexo e a efetividade organizacional é de difícil medição, devido aos diferentes objetivos e interesses de cada stakeholder, que por vezes, se contrapõem. Por este motivo, muitas pesquisas na área de estratégia se voltam para os resultados financeiros (VENKATRAMAN; RAMANUJAM, 1986, apud SILVA et al., 2012) e se baseiam em medidas contábeis (COPELAND et al., 1996, apud SILVA et al., 2012).

Este foi o caso desta pesquisa, uma vez que foram coletados dados contábeis das empresas, como: Receita Líquida, ISP, investimento social, cultural e ambiental -, bem como o valor do investimento total, para se analisar os investimentos em RSE das empresas. Os valores de ISP, investimento social, cultural e ambiental foram nomeados como Investimento em RSE.

A pesquisa mediu numericamente o impacto da recessão - através da comparação entre a variação do PIB e a variação dos investimentos totais e em RSE - e por este motivo, a pesquisa em questão se caracterizou também como uma pesquisa quantitativa.

Os dados utilizados são secundários, uma vez que foram coletados anteriormente para outros propósitos, que não o problema em questão (MALHOTRA, 2011). Estes foram obtidos a partir da análise dos Relatórios Anuais de Sustentabilidade, Relatórios de Administração e as Demonstrações Financeiras Consolidadas de 2010 a 2017 das empresas que compuseram a amostra. Tais relatórios foram obtidos nos sites das próprias empresas analisadas (EDP, 2019a; FIBRIA, 2019a; NATURA, 2019b; ENGIE; 2019a; FLEURY, 2019a; TELEFÔNICA, 2019a; CCR; 2019a; WEG, 2019a; CEMIG, 2019a, ENEL; 2019b,c). 
Após analisar os dados numéricos, buscou-se comparar os resultados com as duas teorias sobre as fontes de desempenho das empresas: a teoria da Organização Industrial e a teoria da Visão Baseada em Recursos.

\subsection{Limitações do Método}

A principal limitação do método utilizado foi a utilização de dados secundários fornecidos pelas empresas, uma vez que o trabalho pode se tornar suscetível à forma como a empresa interpreta e disponibiliza seus dados.

Um exemplo disso é o fato de apenas a Natura, a Engie e a WEG terem especificado separadamente seus investimentos ambientais. Além disso, as empresas podem entender e divulgar o ISP de forma diferente, o que pode ter influenciado as análises.

Outra limitação residiu no tamanho e composição da amostra, pequena e muito variada em relação aos setores analisados. Logo, as generalizações das conclusões devem ser tomadas com cuidado, uma vez que o tamanho da amostra não permite inferências estatísticas adequadas.

Além disso, algumas empresas analisadas possuíam operações fora do Brasil o que pode ter gerado mais distorções, uma vez que o nexo de relacionamento com a recessão no país potencialmente se tornou ainda mais frágil nestes casos.

\subsection{Amostra}

A amostra foi constituída de dez empresas que faziam parte da carteira de 2018 do ISE. A escolha por empresas do índice ISE se deu pelo fato deste ser um índice de sustentabilidade, logo, esperava-se que as empresas que o compõe estivessem mais propensas a considerar o tema em suas decisões. Isso se comprovou pelo fato de que $67 \%$ das companhias da carteira do ISE de 2019 "afirmam revisar e definir seus modelos de negócio adotando como critério suas externalidades (impactos positivos ou negativos não precificados) e prevendo ajustes no curto, médio e longo prazo" e que $98 \%$ "incluíram temas referentes à mudança do clima em suas análises de materialidade nos últimos 3 anos" (B3, 2018).

As dez empresas analisadas nesta pesquisa caracterizaram uma amostra do tipo de conveniência, em função da identificação daquelas que possuíam a maior quantidade de dados em relação a ISP, investimentos sociais, culturais e ambientais, sendo este considerados como Investimento em RSE. As empresas selecionadas foram: EDP, Fibria, Natura, Engie, Fleury, Telefônica, CCR, WEG, CEMIG e Eletropaulo. 
A EDP ENERGIAS DO BRASIL S.A. (EDP Brasil) é uma holding de energia elétrica que opera em toda a cadeia de valor, desde a geração até a distribuição da energia (EDP, 2019c). Segundo a empresa, ela pretende criar valor com foco no longo prazo, pautando sua atuação por princípios e valores éticos que configurem a excelência do desempenho. Além disto, afirmou que seu planejamento estratégico "tem como foco a criação de valor compartilhado (EDP, 2019b). Para isso, além de desenvolver uma profunda e contínua gestão de stakeholders, a empresa adotou o conceito de inovabilidade, que consiste na integração da inovação à sustentabilidade" (EDP, 2019a). Faz parte do ISE desde 2006 (ISE B3, 2019).

A FIBRIA CELULOSE S.A. (Fibria) é uma empresa brasileira que é a maior do mundo na produção de celulose de eucalipto. Destaca-se que as atividades florestais da empresa são baseadas em plantios sustentáveis (FIBRIA, 2019b) e ela faz parte do ISE desde 2009 (ISE B3, 2019). Recentemente, em 14 de janeiro de 2019 a Fibria se fundiu a Suzano Papel e Celulose e esta última passou a ser a nova marca da empresa (EXAME, 2019).

A Natura Cosméticos S.A. (Natura) é a maior multinacional brasileira do setor de cosméticos (NATURA, 2019a). A empresa destacou seu compromisso com o desenvolvimento de produtos que expressem valores e práticas sustentáveis, e isso foi percebido pela Visão 2050, uma série de metas que visam o cumprimento destes compromissos (NATURA, 2019c). A empresa faz parte do ISE desde a criação deste, em 2005 (ISE B3, 2019).

A ENGIE BRASIL ENERGIA S.A. (Engie) é a maior produtora privada de energia elétrica do Brasil, atuando na comercialização desta energia. Destaca-se que o grupo possui $90 \%$ da sua capacidade instalada no Brasil oriunda de fontes limpas, renováveis e com baixas emissões de gases de efeito estufa (ENGIE, 2019b). A empresa faz parte do ISE desde a criação deste, em 2005 (ISE B3, 2019).

A Fleury S.A. (Fleury) é uma empresa brasileira de medicina e saúde. Tem como missão "Prover soluções cada vez mais completas e integradas para a gestão da saúde e o bem-estar das pessoas, com excelência, humanidade e sustentabilidade" (FLEURY, 2019b) Faz parte do ISE desde 2013 (ISE B3, 2019).

A TELEFÔNICA BRASIL S.A. (Telefônica) é uma empresa do setor de telefonia e oferece serviços de internet, telefonia móvel e fixa, além de serviços de TV por assinatura (TELEFÔNICA, 2019b). A empresa assumiu compromissos de desenvolvimento sustentável, que, segundo ela, podem ser percebidos em suas metas (TELEFÔNICA, 2019c). A empresa integra o ISE desde 2012 (ISE B3, 2019).

A CCR S.A. (CCR) é uma das maiores empresas de concessões de infraestrutura da América Latina, trabalhando com concessão de rodovias, mobilidade urbana, aeroportos e serviços, além de atuar no setor de transmissão de dados de alta capacidade (CCR, 2019c). 
Um de seus objetivos estratégicos é manter a sustentabilidade e a satisfação dos usuários dos serviços oferecidos como diferencial da proteção e da criação de valor do negócio (CCR, 2019b). A empresa faz parte do ISE desde a criação deste, em 2005 (ISE B3, 2019).

A WEG S.A. (WEG) é uma empresa do setor de energia. Ela oferece serviços e produtos que incluem geração e distribuição de energia, conversão de energia e automação industrial e Instalações de proteção de instalações elétricas de máquinas. Também atua no setor de tintas, abrangendo tintas industriais, vernizes eletro-isolantes e tintas para repintura automotiva (WEB, 2019b). A empresa citou que seu planejamento estratégico de longo prazo tem como objetivo um crescimento contínuo e sustentável (WEG, 2019b) e integra o ISE desde a criação deste, em 2005 (ISE B3, 2019).

A Companhia Energética de Minas Gerais (CEMIG) é uma empresa da área de energia que atua desde a geração, passando pela transmissão até a distribuição de energia elétrica. É a única empresa do setor da América Latina que faz parte do IDJS (Índice Dow Jones de Sustentabilidade) desde 2000, quando foi a primeira edição deste índice (CEMIG, 2019b) e faz parte do ISE desde a criação deste, em 2005 (ISE B3, 2019).

A ELETROPAULO METROPOLITANA S.A. (Eletropaulo) é uma empresa de distribuição de energia. Em 2018 foi comprada pela Enel e passou a se chamar Enel Distribuição São Paulo (ENEL, 2019a). A empresa destacou valores como responsabilidade, inovação, confiança e proatividade e disse combinar sustentabilidade com inovação para enfrentar os desafios do mundo atual (ENEL, 2019c). Faz parte do ISE desde a criação deste, em 2005 (ISE B3, 2019).

\subsection{Fontes de dados}

Foram coletados dados contábeis entre 2010 a 2017 sobre: Receita Líquida, Investimento em RSE - ISP, investimento social, cultural e ambiental -, bem como o valor do investimento total para se analisar os investimentos de RSE das empresas. Foram coletados dados de antes e de depois da recessão para que pudesse melhor se avaliar a variação destes.

Destaca-se que o conceito sobre ISP pode variar entre as empresas. Além disso, apenas três empresas indicaram separadamente investimentos ambientais.

O valor do investimento total foi obtido através da Demonstração de Fluxo de Caixa, especificamente na conta Caixa Líquido nas Atividades de investimento. Foi considerada apenas a saída de caixa nesta rubrica, como forma de se encontrar o valor efetivamente investido em cada exercício fiscal, e não o retorno obtido com investimentos anteriores. 
Além disso, foram coletados dados sobre a variação anual do PIB - Produto Interno Bruto - para o período considerado, por meio do site do IBGE - Instituto Brasileiro de Geografia e Estatística - e que podem ser encontrados no Anexo (IBGE, 2019).

\subsection{Tratamento e Análise dos dados}

Foram criados agrupamentos para comparar grupos de empresas e identificar semelhanças entre elas, devido ao tipo de indústria em que atuam, como defendido na Organização Industrial, ou outras características que elas pudessem possuir em comum.

Um dos agrupamentos foi baseado na utilização direta de insumos da natureza para os processos operacionais da empresa. Outro agrupamento foi feito com base no grau de governança corporativa de cada empresa, de acordo com classificações correspondentes na B3, em "Novo Mercado" e "Demais Níveis". Além disso, foi efetuado um agrupamento com todas as empresas, buscando uma visão mais geral do relacionamento entre a recessão econômica e os investimentos em RSE para o conjunto da amostra de dez empresas.

As análises foram então efetuadas em quatro etapas, de acordo com o conjunto de empresas: a primeira, para todas as empresas; a segunda, para o agrupamento de acordo com o emprego de insumos da natureza; a terceira, de acordo com o grau de governança corporativa e a última, considerando cada uma das empresas individualmente.

Como forma de encontrar uma possível relação entre a recessão brasileira e a variação da alocação de recursos pelas empresas, comparou-se a variação anual $(\Delta)$ do $\mathrm{PIB}$ com a variação anual $(\Delta)$ da proporção (\%) dos seguintes indicadores: Investimentos/Receita Líquida, Investimento em RSE/Receita Líquida e Investimento em RSE/Investimentos, de cada uma das empresas.

Optou-se pelo emprego de indicadores, ao invés do valor absoluto das rubricas contábeis, a fim de evitar distorções causadas pelo efeito da inflação, permitindo-se assim comparar a variação real destes indicadores com a variação do PIB no período considerado.

A fim de identificar a existência de relacionamentos entre a variação dos indicadores escolhidos e a variação do PIB, usou-se a medida estatística coeficiente de correlação de Pearson ( $\rho)$ entre os anos de 2010 e 2017. A correlação de Pearson "mede o grau de relação linear entre duas variáveis quantitativas" (FIGUEIREDO FILHO; SILVA JUNIOR, 2010).

Devido ao pequeno tamanho da amostra, as correlações não puderam ser consideradas como significativas estatisticamente, mas puderam ser interpretadas como indicações de tendências entre as variáveis. Assim, valores da correlação de Pearson, tanto positivos como negativos, entre 0,10 e 0,29 foram considerados como pequenos, entre 0,30 
e 0,49 como médios, e entre 0,50 e 1 como elevados (FIGUEIREDO FILHO; SILVA JUNIOR, 2010).

Para o cálculo do coeficiente de correlação de Pearson entre as variáveis em cada um dos agrupamentos foi empregada a mediana de cada um dos indicadores em cada agrupamento. 


\section{Apresentação e análise dos resultados}

\subsection{Análise para o conjunto de todas as empresas}

As medianas do coeficiente de correlação de Pearson entre cada um dos indicadores (Variação Investimento/Receita Líquida, Variação Investimento em RSE/Receita Líquida e Variação Investimento em RSE/Investimentos), por empresa e para o conjunto de todas as empresas e a Variação do PIB estão descritas na Tabela 1.

\section{Tabela 1: Mediana do coeficiente de correlação de Pearson - Agrupamento Geral}

\begin{tabular}{|c|c|c|c|}
\hline Empresas & $\begin{array}{c}\boldsymbol{\Delta} \% \text { Investimento/Receita } \\
\text { Líquida }\end{array}$ & $\begin{array}{c}\boldsymbol{\Delta} \% \text { Investimento em } \\
\mathbf{R S E} / \text { Receita Líquida }\end{array}$ & $\begin{array}{c}\boldsymbol{\Delta} \% \text { Investimento em } \\
\text { RSE/lnvestimentos }\end{array}$ \\
\hline EDP & $-0,13$ & $-0,51$ & $-0,40$ \\
\hline Fibria (Suzano S.A) & $-0,84$ & 0,53 & 0,94 \\
\hline Natura & 0,21 & 0,13 & 0,01 \\
\hline Engie & $-0,43$ & 0,48 & 0,54 \\
\hline Fleury & 0,33 & 0,03 & 0,27 \\
\hline Telefônica & 0,03 & 0,01 & $-0,37$ \\
\hline CCR & $-0,40$ & $-0,11$ & 0,51 \\
\hline WEG & $-0,09$ & 0,78 & 0,26 \\
\hline CEMIG & $-0,13$ & 0,23 & 0,20 \\
\hline Eletropaulo & $-0,44$ & 0,03 & 0,35 \\
\hline Mediana & $-\mathbf{0 , 1 3}$ & $\mathbf{0 , 0 8}$ & $\mathbf{0 , 2 7}$ \\
\hline
\end{tabular}

Fonte: Desenvolvida pela autora.

As correlações encontradas entre os indicadores Variação Investimento/Receita Líquida e Variação Investimento em RSE/Receita líquida com variação do PIB foram consideradas pequena $(\rho=-0,13)$ e sem correlação aparente $(\rho=0,08)$, respectivamente. Já o indicador de Variação do Investimento em RSE/Investimentos apresentou uma correlação superior, mas ainda pequena, de 0,27.

Assim, embora sem permitir uma inferência estatisticamente significativa, percebeu-se uma sutil tendência em se variar os Investimentos em RSE, em relação aos investimentos totais, em uma correlação positiva com a variação do PIB. Ao mesmo tempo, constatou-se uma tendência oposta para o indicador Variação Investimento/Receita Líquida.

Ao analisar estes comportamentos em relação ao período da recessão, percebeu-se uma tendência de se aumentar os Investimentos, em relação a Receita Líquida, e de se reduzir Investimentos em RSE, em relação aos investimentos totais, neste período. Destaca- 
se que isto pode ter ocorrido, em função de investimentos de longo prazo já tomados no passado e que necessitam ser mantidos.

A conclusão acompanhou os resultados encontrados por Karaibrahimoğlu (2010), uma vez que as empresas estudadas pelo autor reduziram os investimentos em RSE em épocas de recessão. Entretanto, o resultado foi na direção oposta ao que é sugerido por Wilson (2008, apud KARAIBRAHIMOĞLU, 2010), que afirma que, como resposta a uma recessão, as empresas deveriam focar em atender às necessidades da sociedade e os projetos de RSE poderiam oferecer o suporte necessário para isto.

Como as empresas da amostra faziam parte do ISE e formavam um grupo de empresas que possuía maior vocação para preocupações com RSE, esperava-se que elas buscassem preservar seus investimentos em questões de sustentabilidade em diferentes ambientes econômicos, o que parece não ter ocorrido. Embora os investidores valorizem investimentos sociais e ambientais, por vê-los como algo que pode proporcionar retorno econômico no longo prazo (MILANI FILHO, 2018), diante da recessão, as empresas parecem terem tendido a reduzir este tipo de investimento.

\subsection{Análise para o agrupamento por Grau de Governança na B3}

Este grupo foi constituído de dois tipos de empresas, com base no Grau de Governança na B3, em dois níveis: "Novo Mercado" e "Demais níveis".

$\mathrm{Na}$ categoria "Novo Mercado" foram classificadas as empresas: EDP, Fibria, Natura, Engie, Fleury, CCR, WEG e Eletropaulo. É importante ressaltar que a Fibria se fundiu com a Suzano (EXAME, 2019), passando esta última a ser o nome da empresa, logo, por este motivo, foi usado o grau de governança da Suzano neste agrupamento. Na categoria "Demais níveis" estavam presentes apenas as empresas: Telefônica e CEMIG (B3, 2019).

As medianas do coeficiente de correlação de Pearson para cada um dos indicadores estudados podem ser encontradas na Tabela 2. 


\section{Tabela 2: Mediana Coeficiente de Correlação de Correlação de Pearson - Agrupamento Grau de Governança na B3}

\begin{tabular}{|c|c|c|c|c|}
\hline Categorias & Empresas & $\begin{array}{c}\Delta \% \text { Investimento/Receita } \\
\text { Líquida }\end{array}$ & $\begin{array}{l}\Delta \% \text { Investimento em } \\
\text { RSE/Receita Líquida }\end{array}$ & $\begin{array}{l}\Delta \% \text { Investimento em } \\
\text { RSE/Investimentos }\end{array}$ \\
\hline \multirow{9}{*}{ Novo Mercado } & EDP & $-0,13$ & $-0,51$ & $-0,40$ \\
\hline & Fibria (Suzano S.A) & $-0,84$ & 0,53 & 0,94 \\
\hline & Natura & 0,21 & 0,13 & 0,01 \\
\hline & Engie & $-0,43$ & 0,48 & 0,54 \\
\hline & Fleury & 0,33 & 0,03 & 0,27 \\
\hline & CCR & $-0,40$ & $-0,11$ & 0,51 \\
\hline & WEG & $-0,09$ & 0,78 & 0,26 \\
\hline & Eletropaulo & $-0,44$ & 0,03 & 0,35 \\
\hline & Mediana & $-0,26$ & 0,08 & 0,31 \\
\hline \multirow{3}{*}{ Demais níveis } & Telefônica & 0,03 & 0,01 & $-0,37$ \\
\hline & CEMIG & $-0,13$ & 0,23 & 0,20 \\
\hline & Mediana & $-0,05$ & 0,12 & $-0,08$ \\
\hline $\begin{array}{c}\text { Agrupamento } \\
\text { Geral }\end{array}$ & Mediana & $-0,13$ & 0,08 & 0,27 \\
\hline
\end{tabular}

Fonte: Elaborada pela autora.

Na categoria "Novo Mercado", o indicador Variação do Investimento/Receita Líquida tem mediana para o coeficiente de correlação de $-0,26$, indicando uma correlação negativa pequena. $O$ indicador Variação do Investimento em RSE/Receita Líquida apresentou coeficiente de correlação de 0,08 , não demonstrando indício de relação entre o indicador e a variação do PIB. Já o indicador Variação do Investimento em RSE/Investimentos obteve um coeficiente de correlação de 0,31 , o que representa um indício de uma relação média positivamente correlacionada.

De acordo com os dados acima, percebe-se que as empresas do Novo Mercado tenderam a aumentar os seus investimentos, mesmo diante de possíveis quedas de receitas provocadas pela recessão. O Investimento em RSE/Receita Líquida não sofreu alterações relevantes em comparação às condições de variação do PIB (coeficiente de correlação de 0,08). Finalmente, o indicador Variação do Investimento em RSE/ Investimentos apresentou uma tendência a acompanhar as variações do PIB no país.

Ao se comparar a categoria "Novo Mercado" com o agrupamento geral, percebe-se que as empresas agrupadas na categoria do Novo Mercado apresentaram um coeficiente de correlação com a variação do PIB mais elevada do que o agrupamento geral no indicador Variação do Investimento/Receita Líquida. Tal fato mostra que, durante a recessão, a mediana das empresas da categoria "Novo Mercado" aumentou mais os investimentos em relação à Receita Líquida, do que a mediana de todas as empresas estudadas.

Em relação à categoria "Demais níveis", o indicador Variação do Investimento/Receita Líquida apresentou coeficiente de correlação de $-0,05$, não evidenciando uma relação entre a variação do indicador e a variação do PIB. Da mesma forma, o indicador Variação do 
Investimento em RSE/Receita Líquida apresentou um coeficiente de correlação pequeno, de 0,12 e o indicador Variação do Investimento em RSE/Investimentos apresentou um coeficiente de correlação também reduzido, de $-0,08$, caracterizando uma tendência à inexistência de relação entre a variação deste indicador e a variação do PIB.

Ao se comparar a categoria "Demais níveis" com o agrupamento geral, percebe-se que a primeira apresenta uma correlação positiva menor no indicador Variação do Investimento em RSE /Receita Líquida, enquanto o agrupamento geral apresentou aumento dos investimentos em relação à Receita Líquida e redução do Investimento em RSE em relação aos Investimentos.

A categoria "Novo Mercado" diz respeito ao mais elevado nível de governança na B3 (BM\&FBOVESPA, 2019a) e, além disso, práticas de RSE são associadas a uma boa governança corporativa (OECD, 2004, apud KARAIBRAHIMOĞLU, 2010). Por este motivo esperava-se que as empresas da categoria "Novo Mercado" tendessem a manter seus investimentos em RSE, mesmo durante uma recessão. No entanto, na prática isso não ocorreu e a categoria reduziu seus Investimentos em RSE, em relação aos investimentos totais, um pouco mais fortemente do que a categoria "Demais Níveis".

\subsection{Análise para o agrupamento por utilização de insumos da natureza}

Neste agrupamento, as empresas foram classificadas com relação a utilização, direta ou indireta de insumos da natureza. Na categoria "Utiliza diretamente" estavam presentes empresas que utilizam diretamente em seus processos operacionais, insumos da natureza e de maneira significativa, como: Fibria, Natura, Engie e CEMIG. Já na categoria "Não utiliza diretamente" estavam EDP, Fleury, Telefônica, CCR, WEG e Eletropaulo.

As medianas do coeficiente de correlação de Pearson para cada um dos indicadores estudados podem ser observados na Tabela 3. 
Tabela 3: Coeficiente de correlação de Pearson -

Agrupamento Utilização de insumos da natureza

\begin{tabular}{|c|c|c|c|c|}
\hline Categorias & Empresas & $\begin{array}{c}\Delta \% \text { Investimento/Receita } \\
\text { Líquida }\end{array}$ & $\begin{array}{l}\Delta \% \text { Investimento em } \\
\text { RSE/Receita Líquida }\end{array}$ & $\begin{array}{l}\Delta \% \text { Investimento em } \\
\text { RSE/Investimentos }\end{array}$ \\
\hline \multirow{5}{*}{$\begin{array}{c}\text { Utiliza } \\
\text { diretamente }\end{array}$} & Fibria & $-0,84$ & 0,53 & 0,94 \\
\hline & Natura & 0,21 & 0,13 & 0,01 \\
\hline & Engie & $-0,43$ & 0,48 & 0,54 \\
\hline & CEMIG & $-0,13$ & 0,23 & 0,20 \\
\hline & Mediana & $-0,28$ & 0,35 & 0,37 \\
\hline \multirow{7}{*}{$\begin{array}{c}\text { Não utiliza } \\
\text { diretamente }\end{array}$} & EDP & $-0,13$ & $-0,51$ & $-0,40$ \\
\hline & Fleury & 0,33 & 0,03 & 0,27 \\
\hline & Telefônica & 0,03 & 0,01 & $-0,37$ \\
\hline & CCR & $-0,40$ & $-0,11$ & 0,51 \\
\hline & WEG & $-0,09$ & 0,78 & 0,26 \\
\hline & Eletropaulo & $-0,44$ & 0,03 & 0,35 \\
\hline & Mediana & $-0,11$ & 0,02 & 0,27 \\
\hline $\begin{array}{c}\text { Agrupamento } \\
\text { Geral }\end{array}$ & Mediana & $-0,13$ & 0,08 & 0,27 \\
\hline
\end{tabular}

Fonte: Elaborada pela aluna.

Em relação à categoria "Utiliza diretamente", o indicador Variação do Investimento/Receita Líquida apresentou coeficiente de correlação de -0,28, indicando uma correlação negativa pequena. $O$ indicador Variação do Investimento em RSE/Receita Líquida obteve coeficiente de correlação de 0,35 , demonstrando uma correlação positiva média. Já o coeficiente de correlação para o indicador Variação do Investimento em RSE/Investimentos foi de 0,37 , indicando, também, uma correlação positiva média.

Tais dados mostram que as empresas da categoria "Utiliza diretamente" tiveram uma sutil tendência de investir mais durante a recessão, mas reduziram o Investimento em RSE, o que pode mostrar que estas empresas veem o Investimento como forma de reagir à recessão, mas podem perceber o Investimento em RSE como um dispêndio que pode ser reduzido, mesmo sendo relevantes para suas operações..

Ao se analisar as variações ocorridas nos montantes dos investimentos em RSE pela ótica da teoria da Organização Industrial, esperava-se que empresas da categoria que utiliza diretamente insumos da natureza investissem mais em ações de RSE, principalmente em investimentos ambientais, mesmo em recessões, uma vez que as estruturas das indústrias contempladas nesta categoria dependem mais deste tipo investimento na natureza (PORTER, 1981). No entanto, as empresas desta categoria tenderam a reduzir investimentos em RSE em uma intensidade maior, inclusive, do que empresas da categoria "Não utilizam diretamente", o que vai contra as expectativas decorrentes da aplicação da teoria.

Já na categoria "Não utiliza diretamente", o indicador Variação do Investimento/Receita Líquida obteve coeficiente de correlação de -0,11, representando uma 
correlação negativa pequena; o indicador Variação do Investimento em RSE/Receita Líquida apresentou coeficiente de correlação de 0,02 , indicando que não há uma correlação com a variação do PIB; e o coeficiente de correlação do indicador Variação do Investimento em RSE/Investimentos foi de 0,27 , o que demonstra uma correlação positiva pequena.

Estes dados indicam que as empresas da categoria "Não utilizam diretamente" tenderam sutilmente a investir mais, em relação à Receita Líquida, durante a recessão. No entanto, apesar deste sutil aumento no Investimento/Receita Líquida, a proporção de Investimento em RSE/Investimentos diminuiu. Isso demonstra que estas empresas, durante a recessão, podem ter visto o Investimento como forma de resposta à recessão, mas não enxergaram o Investimento em RSE da mesma forma, possivelmente considerando-o como um dispêndio a ser reduzido.

A categoria "Não utiliza diretamente" apresentou comportamento similar ao agrupamento geral para todos os indicadores estudados.

Ao se comparar as duas categorias, percebe-se que o comportamento de ambas foi similar, com a diferença de que as empresas da categoria "Não utiliza diretamente" não reduziram Investimento em RSE/Receita Líquida.

\subsection{Análise individual de empresas}

Neste tópico foram selecionadas para análise somente empresas que apresentaram coeficientes de correlação elevados $(\rho \geq 0,5$ ou $\rho \leq-0,5)$ em qualquer um dos indicadores. Foi usado este critério para seleção, uma vez que estas apresentaram uma relação mais forte com a variação do PIB e, consequentemente, com a recessão, que é o objeto desta pesquisa. As empresas analisadas foram: EDP, Fibria, Engie, CCR e WEG. As tabelas completas com os resultados específicos para todas as empresas da amostra estão no Anexo.

\section{Tabela 4: Coeficiente de correlação - EDP}

\begin{tabular}{|c|c|c|}
\hline $\begin{array}{c}\Delta \% \text { Investimentol } \\
\text { Receita Líquida }\end{array}$ & $\begin{array}{c}\Delta \% \text { Investimento em } \\
\text { RSE/Receita Líquida }\end{array}$ & $\begin{array}{c}\Delta \% \text { Investimento em } \\
\text { RSE/Investimentos }\end{array}$ \\
\hline$-0,13$ & $-0,51$ & $-0,40$ \\
\hline
\end{tabular}

Fonte: Elaborada pela autora.

A EDP apresentou coeficiente de correlação de -0,51 para o indicador Variação Investimento em RSE/Receita Líquida e a variação do PIB. Tal dado mostra que a EDP teve uma tendência de aumentar o Investimento em RSE mesmo durante a recessão, sendo a única empresa a ter uma correlação negativa tão elevada para este indicador. 
Tal empresa apresentou uma elevada diferença com a mediana do coeficiente de correlação do agrupamento geral com todas as empresas, que foi de 0,08 , para este indicador. Também apresenta elevada diferença com outras categorias das quais fez parte nas análises, como o "Novo Mercado" e "Não utiliza diretamente", uma vez que nestes dois agrupamentos, a correlação do indicador com a variação do PIB foi muito reduzida.

A empresa também apresentou relação negativa entre o indicador Variação do Investimento em RSE/Investimentos e a variação do PIB, indicando que pode ter percebido o investimento e o Investimento em RSE como uma forma de resposta à recessão.

É importante destacar que a empresa apresentou variações expressivas em alguns indicadores entre os anos de 2015 e 2016, período no qual houve aumento de $432 \%$ no indicador Variação do Investimento em RSE/Receita Líquida e $246 \%$ no indicador Variação do Investimento em RSE/Investimentos. Tal aumento nos investimentos pode ter feito parte do planejamento estratégico da empresa, de unir cada vez mais inovação e sustentabilidade aos seus negócios.

A EDP diz que tem como foco a criação de valor no longo prazo e como descrito (EDP, 2019b), investimentos em RSE podem garantir melhores desempenhos no longo prazo. Além disso, a criação de valor compartilhado para seus stakeholders e a integração entre inovação e sustentabilidade fazem parte de seu planejamento estratégico (EDP, 2019a). Sob a ótica da VBR, então, pode-se dizer que o investimento em RSE é visto pela empresa como uma forma de obtenção de vantagem competitiva e os dados encontrados corroboram com tal visão (AMIT; SCHOEMAKER, 1993; DIERICKX; COOL, 1989; PENROSE, 1959; PETERAF, 1993; WERNERFELT, 1984, apud SILVA et al., 2012).

A Fibria foi a única empresa que apresentou uma correlação elevada para todos os indicadores analisados, como pode ser observado na Tabela 5.

\section{Tabela 5: Coeficiente de correlação - Fibria}

\begin{tabular}{|c|c|c|}
\hline $\begin{array}{c}\Delta \% \text { Investimentol } \\
\text { Receita Líquida }\end{array}$ & $\begin{array}{c}\Delta \% \text { Investimento em } \\
\text { RSE/Receita Líquida }\end{array}$ & $\begin{array}{c}\Delta \% \text { Investimento em } \\
\text { RSE/Investimentos }\end{array}$ \\
\hline$-0,84$ & 0,53 & 0,94 \\
\hline
\end{tabular}

Fonte: Elaborada pela autora.

Os indicadores Variação do Investimento/Receita Líquida, Variação do Investimento em RSE/Receita Líquida e Variação do Investimento em RSE/Investimentos, apresentaram coeficiente de correlação de -0,84, 0,53 e 0,94, respectivamente. Assim, notou-se um aumento do Investimento/Receita Líquida durante a recessão, ao mesmo tempo em que há redução do Investimento em RSE/Investimentos e do Investimento em RSE/Receita Líquida. 
Isso mostra que a empresa pode ter visto o investimento como forma de enfrentar a recessão, mas não viu o Investimento em RSE na mesma forma, podendo, inclusive, tê-lo visto como um desembolso a ser reduzido.

Tal tendência vai de acordo com a tendência do agrupamento geral. No entanto, para a Fibria a correlação foi mais elevada para todos os indicadores. A Fibria também apresentou correlação mais elevada do que a mediana de todos os indicadores para todos as categorias das quais faz parte - "Novo Mercado" e "Utiliza diretamente".

É importante analisar o comportamento da Fibria pela ótica da VBR, que afirma que as características individuais das empresas são determinantes para o seu desempenho (AMIT; SCHOEMAKER, 1993; DIERICKX; COOL, 1989; PENROSE, 1959; PETERAF, 1993; WERNERFELT, 1984, apud SILVA et al., 2012). A Fibria é uma empresa que atua diretamente empregando recursos da natureza (principalmente as plantações de eucaliptos) com atividades baseadas em plantios sustentáveis (FIBRIA, 2019b), sendo isto base de vantagem competitiva. Por este motivo esperava-se que a empresa mantivesse seus investimentos em RSE, mesmo que em épocas de recessão. No entanto, os dados encontrados demonstram uma tendência oposta.

\section{Tabela 6: Coeficiente de correlação - Engie}

\begin{tabular}{|c|c|c|}
\hline $\begin{array}{c}\Delta \% \text { Investimentol } \\
\text { Receita Líquida }\end{array}$ & $\begin{array}{c}\Delta \% \text { Investimento em } \\
\text { RSE/Receita Líquida }\end{array}$ & $\begin{array}{c}\Delta \% \text { Investimento em } \\
\text { RSE/Investimentos }\end{array}$ \\
\hline$-0,43$ & 0,48 & 0,54 \\
\hline
\end{tabular}

Fonte: Elaborada pela autora.

A Engie apresentou coeficiente de correlação de 0,54 para o indicador Variação do Investimento em RSE/Investimentos, como indicado na Tabela 6, demonstrando uma elevada correlação positiva com a variação do PIB. A empresa também apresentou correlação negativa média para o indicador Variação do Investimento/Receita Líquida ( $\rho=$ 0,43) e correlação positiva média para o indicador Variação do Investimento em RSE/Receita Líquida $(\rho=0,48)$. Tais dados indicam que a empresa aumentou os investimentos, em relação à Receita Líquida, durante a recessão, mas reduziu tanto a proporção do Investimento em RSE/Receita Líquida como a do Investimento em RSE/Investimentos. Tais observações podem indicar que a empresa pode ter visto o investimento como forma de enfrentar a recessão, mas não considerou o Investimento em RSE sob a mesma ótica. 
A Engie apresentou coeficiente de correlação mais elevada do que a mediana de todos os indicadores para todas as categorias das quais faz parte - "Novo Mercado" e "Utiliza diretamente", como indicado na Tabela 6.

A Engie, assim como a Fibria, utiliza diretamente recursos da natureza e, além disso, possui $90 \%$ da sua capacidade instalada no Brasil originária de insumos de fontes limpas, renováveis e produtores de baixas emissões de gases de efeito estufa (ENGIE, 2019b). Logo estes recursos, por serem difícil de cópia, são essenciais para manter as vantagens competitivas da empresa. Por este motivo, era esperado que a empresa mantivesse seus Investimentos em RSE, especialmente investimentos ambientais, mesmo durante a recessão, porém, na prática, a empresa reduziu estes investimentos.

\section{Tabela 7: Coeficiente de correlação - CCR}

\begin{tabular}{|c|c|c|}
\hline $\begin{array}{c}\Delta \% \text { Investimento/ } \\
\text { Receita Líquida }\end{array}$ & $\begin{array}{c}\Delta \% \text { Investimento em } \\
\text { RSE/Receita Líquida }\end{array}$ & $\begin{array}{c}\Delta \% \text { Investimento em } \\
\text { RSE/Investimentos }\end{array}$ \\
\hline$-0,40$ & $-0,11$ & 0,51 \\
\hline
\end{tabular}

Fonte: Elaborada pela autora.

A CCR apresentou coeficiente de correlação de 0,51 para o indicador Variação do Investimento em RSE/Investimentos, como pode ser visto na Tabela 7, representando uma correlação positiva elevada. Além disso, apresentou correlação negativa média $(\rho=-0,40)$ para o indicador Variação do Investimento/Receita Líquida. Os dados citados mostram que a empresa aumentou a proporção de investimentos em relação à Receita Líquida durante a recessão, e também aumentou o Investimento em RSE. Porém, o aumento de Investimentos foi maior, proporcionalmente, que o aumento de Investimento em RSE e por isso houve redução da proporção de Investimento em RSE nos Investimentos totais, indicando que a empresa priorizou outros tipos de investimentos ao Investimento em RSE.

O resultado parece estar em acordo com a tendência do agrupamento geral, mas a CCR apresentou correlação mais elevada para todos os indicadores. Em relação às outras categorias das quais faz parte - "Novo Mercado" e "Não utiliza diretamente"-, a CCR apresenta correlação maior para todos os indicadores, em todas as categorias.

Um dos objetivos declarados pela CCR é manter a sustentabilidade como forma de criar valor ao negócio (CCR, 2019b). Analisando tal afirmação pela ótica da VBR, percebese que a empresa avalia a sustentabilidade como forma de garantir sua vantagem competitiva (AMIT; SCHOEMAKER, 1993; DIERICKX; COOL, 1989; PENROSE, 1959; PETERAF, 1993; WERNERFELT, 1984, apud SILVA et al., 2012). No entanto, na prática, a empresa tendeu a reduzir os investimentos em RSE durante a recessão. 
Tabela 8: Coeficiente de correlação - WEG

\begin{tabular}{|c|c|c|}
\hline $\begin{array}{c}\Delta \% \text { Investimentol } \\
\text { Receita Líquida }\end{array}$ & $\begin{array}{c}\Delta \% \text { Investimento em } \\
\text { RSE/Receita Líquida }\end{array}$ & $\begin{array}{c}\Delta \% \text { Investimento em } \\
\text { RSE/Investimentos }\end{array}$ \\
\hline$-0,09$ & 0,78 & 0,26 \\
\hline
\end{tabular}

Fonte: Elaborada pela autora.

A WEG obteve coeficiente de correlação de 0,78 para o indicador Variação do Investimento em RSE/Receita Líquida, conforme especificado na Tabela 8, indicando uma relação positiva elevada com a variação do PIB. Já para o indicador Variação do Investimento /Receita Líquida, não se constatou relação com a variação do PIB e para o indicador Variação do Investimento em RSE/Investimentos encontrou-se uma correlação positiva pequena. A proporção dos investimentos em relação a Receita Líquida não sofreu significativas mudanças durante a recessão, mas o Investimento em RSE apresentou reduções expressivas, o que indica que a empresa pode avaliar seus investimentos em RSE como gastos a serem reduzidos em épocas de recessão.

De acordo com a tendência do agrupamento geral, a WEG também tendeu a reduzir seus investimentos totais durante a recessão. No entanto, a empresa não aumentou os investimentos em relação a Receita Líquida, o que difere da tendência percebida do agrupamento geral.

Em relação às categorias "Novo Mercado" e "Não utiliza diretamente" das quais a WEG faz parte, a empresa apresenta tendências similares à mediana para os indicadores Variação do Investimento/Receita Líquida e Variação do Investimento em RSE/Investimentos. Porém para o indicador Variação do Investimento em RSE/Receita Líquida a empresa apresenta uma grande diferença, uma vez que se constata uma correlação positiva elevada na WEG e para as categorias não foi percebida uma correlação.

A empresa destacou como parte de seu planejamento estratégico de longo prazo o objetivo de obter um crescimento contínuo e sustentável e, como destacado, investimentos em RSE podem gerar retornos econômicos superiores no longo prazo (WEG, 2019b). Assim, sob a ótica da VBR, percebe-se que a WEG poderia avaliar o Investimento em RSE como uma forma de obter vantagens competitivas (AMIT; SCHOEMAKER, 1993; DIERICKX; COOL, 1989; PENROSE, 1959; PETERAF, 1993; WERNERFELT, 1984, apud SILVA et al., 2012). No entanto, os dados mostram que na prática isso não ocorreu. 


\section{Conclusões}

Mudanças externas às empresas como a crescente preocupação de diferentes stakeholders com questões ambientais e sociais, a visão de que o investimento nestas questões pode garantir retornos econômicos no longo prazo e o desenvolvimento de padrões para que sejam mensuradas financeiramente, fizeram com que empresas voltem sua atenção para questões de RSE. Juntamente à crescente importância do tema, recentemente o Brasil viveu uma recessão entre 2014 e 2016.

A pesquisa efetuada buscou analisar o efeito da recessão brasileira entre 2014 e 2016 sobre os investimentos em RSE realizado pelas empresas, buscando responder à pergunta:

- Há relação entre os investimentos em RSE e a variação do PIB no Brasil?

Para responder a esta pergunta foram escolhidas 10 empresas integrantes da carteira do ISE para o ano de 2018 e utilizados os dados contábeis presentes em seus Relatórios de Sustentabilidade e Demonstrações financeiras, bem como os dados da variação do PIB, fornecidos pelo IBGE. Foram analisados dados como Receita Líquida, Investimentos e Investimento em RSE - ISP, investimento ambiental, cultural, social - e variação do PIB entre os anos de 2010 e 2017.

Em seguida, foram criados agrupamentos para fazer uma melhor comparação entre as empresas e visualizar semelhanças ou tendências entre as empresas, de acordo com certas características. Os agrupamentos foram: "Grau de governança na B3", e "Utilização de insumos da natureza".

Através das análises constatou-se uma tendência a se estabelecer uma correlação negativa entre variação do PIB e a variação do Investimento/Receita Líquida, demonstrando uma tendência de se aumentar investimentos durante a recessão. Isto pode ter ocorrido, em função de compromissos de investimentos já tomados no passado e que precisaram ser mantidos ainda que diante de uma contração da economia.

Ao mesmo tempo, percebeu-se uma correlação positiva entre a variação do Investimento em RSE/Investimentos, ou seja, as empresas tenderam a reduzir investimentos em RSE, em relação aos investimentos totais, durante este período diante da variação do PIB, indicando que investimentos em RSE podem ser mais sacrificados em recessões do que os investimentos em geral. Isto indica que as empresas estudadas, em geral, podem ter visto o aumento de investimentos como uma forma de resposta à recessão, 
mas não perceberam os investimentos em RSE da mesma forma, podendo tê-los visto, inclusive, como um gasto a ser reduzido.

Destaca-se ainda que o mesmo comportamento foi percebido em todos os agrupamentos propostos, e isso mostra que esta conduta, não pode ser esclarecida por perspectivas como a da Organização Industrial ou da VBR, pois foi motivada por uma questão mais ampla, a recessão, que se superpôs de forma dominante, tanto sobre a dinâmica industrial como sobre as estratégias de longo prazo das empresas.

É importante ressaltar que as empresas analisadas faziam parte de um índice de sustentabilidade, o ISE, e por este motivo esperava-se que elas mantivessem (ou pelo menos não reduzissem muito), os seus investimentos em RSE, mesmo durante a recessão. No entanto, os resultados mostraram que este não foi o caso. As empresas aqui estudadas tenderam a reduzi-lo.

Em relação a possibilidades futuras de pesquisa, sugere-se que o estudo seja ampliado, buscando resolver a principal limitação da pesquisa derivada do pequena tamanho da amostra, que não permitia inferências estatísticas.

Também sugere-se analisar diferentes tipos de investimento em RSE e não apenas o valor destes, elaborando-se assim, um estudo mais qualitativo em dimensões sociais, ambientais etc.

Outra possibilidade é estudar o motivo das empresas estudadas, mesmo sendo integrantes de um índice de sustentabilidade e citarem dimensões de RSE em suas estratégias, tenderem a reduzir seus investimentos relacionados ao tema durante a recessão.

Para as empresas, uma importante questão se associa aos seus direcionamentos estratégicos. Se por um lado eles precisam ser consistentes e seguidos continuamente, como as preocupações e atuações socioambientais, a prática indicou que fatores econômicos são muitas vezes prevalecentes em relação a tais planos de longo prazo, o que pode contribuir para desempenhos aquém do esperado para todos os seus stakeholders. 


\section{Referências Bibliográficas}

B3. Ações. Disponível em:

$<\mathrm{http} / / /$ www.b3.com.br/pt_br/produtos-e-servicos/negociacao/renda-variavel/empresaslistadas.htm>. Acesso em: 20 de abril de 2019.

B3. Carteira do ISE. 29 de novembro de 2018. Disponível em: <http://www.b3.com.br/pt_br/noticias/carteira-do-ise.htm>. Acesso em: 11 de maio de 2019.

BM\&FBOVESPA. Índice de Sustentabilidade Empresarial (ISE). Disponível em:

$<$ http://www.bmfbovespa.com.br/pt_br/produtos/indices/indices-de-sustentabilidade/indicede-sustentabilidade-empresarial-ise.htm>. Acesso em: 20 de novembro de 2018.

BM\&FBOVESPA. Novo Mercado. Disponível em:

$<$ http://www.bmfbovespa.com.br/pt_br/listagem/acoes/segmentos-delistagem/novo-mercado/>. Acesso em: 25 de maio de 2019a.

BM\&FBOVESPA. Sobre segmentos de Listagem. Disponível em: <http://www.bmfbovespa.com.br/pt_br/listagem/acoes/segmentos-delistagem/sobre-segmentos-de-listagem/>. Acesso em: 25 de maio de $2019 \mathrm{~b}$.

CARRIÇO, F. A.; KIRSHNER, A. M. Investimento Social Privado (ISP) - Questões Atuais. VI Congresso Nacional de Excelência Em Gestão, Niterói, p.1-20, 2010.

CARVALHO, S.; De BENEDICTO, S.C. Surgimento e evolução da responsabilidade social empresarial: uma reflexão teórico-analítica. XXVIII ENCONTRO NACIONAL DE ENGENHARIA DE PRODUÇÃO, 2018.

CCR. Central de Resultados. Disponível em:

<http://ri.ccr.com.br/divulgacao-e-resultados/central-de-resultados/>. Acesso em: 09 de março de 2019a.

CCR. Estratégia de sustentabilidade. Disponível em:

<http://www.grupoccr.com.br/ri2016/pt/estrategia-de-sustentabilidade.html>. Acesso em: 11 de maio de $2019 \mathrm{~b}$.

CCR. Sobre o Grupo CCR. Disponível em:

<http://www.grupoccr.com.br/grupo-ccr/sobre-o-grupo-ccr>. Acesso em: 11 de maio de 2019c.

CEMIG. Central de Downloads. Disponível em:

<http://ri.cemig.com.br/ptb/s-17-ptb.html>. Acesso em: 09 de março de 2019a.

CEMIG. Quem somos. Disponível em:

<http://ri.cemig.com.br/static/ptb/quem_somos.asp?idioma=ptb>. Acesso em: 11 de maio de 2019b. 
CODACE. Comitê de Datação de Ciclos Econômicos. Rio de Janeiro, 2017. Disponível em:

<https://portalibre.fgv.br/data/files/F3/C1/F8/E8/A18F66108DDC4E66CA18B7A8/

Comite\%20de\%20Data_0\%20de\%20Ciclos\%20Econ_micos\%20-

\%20Comunicado\%20de\%2030_10_2017\%20_1_.pdf>. Acesso em: $11 \mathrm{de}$

fevereiro de 2019.

CONNER, K. R. A historical comparison of resource-based theory and five schools of thought within industrial organization economics: do we have a new theory of the firm? Journal of Management, Beverly Hills, v. 17, n. 1, p. 121-154, 1991.

DAHLSRUD, A. How corporate social responsibility is defined: an analysis of 37 definitions. Corporate Social Responsibility \& Environmental Management, [s. I.], v. 15, n. 1 , p. 1-13, 2008.

DECLOEDT, C. 30 empresas que participam do Índice de Sustentabilidade da Bolsa. Exame, São Paulo, 23 nov. 2017. Disponível em:

$<$ https://exame.abril.com.br/mercados/b3-anuncia-30-empresas-para-a-carteira-do-ise-20182019/>. Acesso em 22 de novembro de 2018.

DOUGLAS, B.; ECCLES, R.; HANSELL, G.; LESSER, R.; UNNIKRISHNAN, S.; WOODS, W.; YOUNG, D. Total Societal Impact: A New Lens for Strategy. BCG, 25 outubro 2017. Disponível em: <http://image-src.bcg.com/lmages/BCG-

Total-Societal-Impact-Oct-2017_tcm15-210654.pdf>. Acesso em: 06 de março de 2019.

EDP Brasil. Relatórios Anuais. Disponível em:

$<$ http://enbr.infoinvest.com.br/ptb/relatorios-anuais>. Acesso em: 09 de março de 2019a.

EDP Brasil. Sustentabilidade. Disponível em:

$<$ https://www.edp.com/pt-pt/sustentabilidade-4>. Acesso em: 09 de março de 2019b.

EDP Brasil. Uma empresa líder no setor da energia. Disponível em:

$<$ https://brasil.edp.com/pt-br/sub-homepage-edp-brasil>. Acesso em: 11 de maio de 2019c.

Enel. A Eletropaulo agora é Enel. Disponível em:

$<$ https://www.eneldistribuicaosp.com.br/eletropaulo-agora-e-enel>. Acesso em: 11 de maio de 2019a.

Enel. Central de Resultados. Disponível em:

<http://ri.eneldistribuicaosp.com.br/listresultados.aspx?idCanal=0apyXXoBMDG9EGd5M7My $w w==>$. Acesso em: 01 de maio de 2019b.

Enel. Relatório de Sustentabilidade. Disponível em:

$<$ https://www.eneldistribuicaosp.com.br/relatorio-de-sustentabilidade>. Acesso em: $01 \mathrm{de}$ maio de 2019c.

Engie. Releases e Apresentações de Resultados. Disponível em:

<https://www.engie.com.br/investidores/eventos-e-apresentacoes/releases-e-apresentacoesde-resultados/>. Acesso em: 09 de março de 2019a.

Engie. Sobre a Engie. Disponível em: 
$<$ https://www.engie.com.br/institucional/sobre-a-engie/>. Acesso em: 11 de maio de 2019b.

EXAME. Suzano confirma conclusão de fusão com a Fibria. 14 de janeiro de 2019. Disponível em <https://exame.abril.com.br/negocios/suzano-confirma-conclusao-de-fusaocom-a-fibria/>. Acesso em: 11 de maio de 2019.

Fibria. Central de Downloads. Disponível em:

$<$ https://ri.fibria.com.br/servicos-aos-investidores/central-de-downloads>.

Acesso em: 09 de março de 2019a.

Fibria. Quem somos. Disponível em:

<http://fibria-institucional-qa.azurewebsites.net/institucional/sobre-a-fibria/>.

Acesso em: 11 de maio de 2019b.

FIGUEIREDO FILHO, D. B.; SILVA JUNIOR, J. A. Desvendando os Mistérios do Coeficiente de Correlação de Pearson isso. Revista Política Hoje - ISSN: 0104-7094, [S.I.], v. 18, n. 1, Janeiro de 2010. ISSN 0104-7094.

Fleury. Central de Downloads. Disponível em:

<http://ri.fleury.com.br/fleury/web/conteudo_pt.asp?idioma=0\&conta=28\&tipo=28

897\#>. Acesso em: 09 de março de 2019a.

Fleury. Perfil. Disponível em:

<http://www.grupofleury.com.br/SitePages/perfil/default.aspx>. Acesso em: $11 \mathrm{de}$ maio de 2019b.

Fundo Monetário Internacional. A resposta do FMI à crise econômica mundial, 2012. Disponível em:

$<$ https://www.imf.org/external/lang/portuguese/np/exr/facts/changingp.pdf >.

Acesso em: 11 de fevereiro de 2019.

GARA, A. 10 maiores fraudes da história recente dos Estados Unidos. Forbes, 29 de setembro de 2015. Disponível em:

$<$ https://forbes.uol.com.br/fotos/2015/09/10-maiores-fraudes-da-historia-recente-dosestados-unidos/\#foto3>. Acesso em: 15 de dezembro de 2019.

Instituto Brasileiro de Geografia e Estatística. Séries Históricas. Disponível em: <https://www.ibge.gov.br/estatisticas/economicas/contas-nacionais/9300-contas-nacionaistrimestrais.html?=\&t=series-historicas $>$. Acesso em: 11 de maio de 2019.

ISE B3. Carteiras e Questionários. Disponível em:

<http://iseb3.com.br/carteiras-e-questionarios-1>. Acesso em: 11 de maio de 2019.

KARAIBRAHIMOĞLU, ZENGIN, Y. Corporate social responsibility in times of financial crisis. African Journal of Business Management. [s.I.] Vol. 4, No. 4. Pp. 382-389, 2010.

MALHOTRA, N. K. Pesquisa de Marketing: Foco na Decisão. 3. Ed. São Paulo: Pearson Prentice Hall, 2011.

MANZATO, J.; SANTOS, A. A elaboração de questionários na pesquisa quantitativa. Unesp, 2011.

MILANI FILHO, M. A. F. Responsabilidade social e investimento social privado: entre o discurso e a evidenciação / Social responsibility and private social investment: between 
discourse and disclosure. Revista Contabilidade \& Finanças, [s. I.], n. 47, p. 89, 2008.

National Bureau of Economic Research. About the NBER. Disponível em:

$<$ https://www.nber.org/info.html>. Acesso em: 30 de junho de 2019.

National Bureau of Economic Research.The NBER's Business Cycle Dating Committee. Cambridge, 2010. Disponível em:

<https://www.nber.org/cycles/recessions.html>. Acesso em: 30 de junho de 2019.

Natura. A Natura. Disponível em:

$<$ https://www.natura.com.br/a-natura>. Acesso em 11 de maio de 2019a.

Natura. Central de Downloads. Disponível em:

$<$ https://natu.infoinvest.com.br/servicos-aos-investidores/central-de-downloads $>$. Acesso em 09 de março de 2019b.

Natura. Sustentabilidade. Disponível em:

$<$ https://www.natura.com.br/sustentabilidade>. Acesso em 11 de maio de 2019c.

PORTER, M. E. Capital Choices: Changing the way America invests in industry. Journal of Applied Corporate Finance, 5: 4-16, 1992.

PORTER, M. E. O que é estratégia? Harvard Business Review, 61-78, 1996.

PORTER, M. E. The contributions of industrial organization to strategic management. Academy of Management Review, v. 6, n. 4, p. 609-20, 1981.

SAITO, Richard; SILVEIRA, Alexandre Di Miceli da. Governança corporativa: custos de agência e estrutura de propriedade. Rev. adm. empres., São Paulo, v. 48, n. 2, p. 79-86, junho de 2008.

SARTORE, M. de S. Da filantropia ao investimento socialmente responsável: novas distinções / From philanthropy to socially responsible investment: new distinctions / De la philantropie a l'investissement socialement responsible: de nouvelles distinctions. Caderno CRH, [s. I.], n. 66, p. 451, 2012.

SILVA, Martim Francisco de Oliveira e; SILVA, Jorge Ferreira da; MOTTA, Luiz Felipe Jacques da. A vantagem competitiva das nações e a vantagem competitiva das empresas: 0 que importa na localização? Rev. Adm. Pública, Rio de Janeiro, v. 46, n. 3, p. 701720, junho 2012.

SOBRAL, F; PECl, A. Administração: teoria e prática no contexto brasileiro - São Paulo: Pearson Prentice Hall, 2008.

SOBRAL, F; PECI, A. Administração: teoria e prática no contexto brasileiro - São Paulo: Pearson Prentice Hall, 2012.

SOBRAL, F; PECI, A. Administração: teoria e prática no contexto brasileiro - São Paulo: Pearson Prentice HOall, 2013.

Telefônica. Central de Resultados. Disponível em:

$<$ http://ri.telefonica.com.br/pt/informacoes-ao-mercado/central-de-resultados $>$. Acesso em: 09 de março de 2019a.

Telefônica. Quem somos. Disponível em: 
<http://www.telefonica.com.br/servlet/Satellite?c=Page\&cid=1386090999162\&pagename=In stitucionalVivo\%2FPage\%2FTemplateConteudo>. Acesso em: 11 de maio de 2019b.

Telefônica. Sustentabilidade. Disponível em:

<http://www.telefonica.com.br/servlet/Satellite?c=Page\&cid=1386090999162\&pagename=In stitucionalVivo\%2FPage\%2FTemplateConteudo >. Acesso em: 11 de maio de 2019c.

VIEIRA, Valter A. As tipologias, variações e características da pesquisa de marketing. Revista da FAE, Curitiba, v. 5, n. 1, p. 61-70, jan./abr. 2002.

WEG. Central de Resultados. Disponível em:

$<$ https://ri.weg.net/informacoes-financeiras/central-de-resultados\#2019>. Acesso em: 09 de março de 2019a.

WEG. Nossos negócios. Disponível em:

<https://www.weg.net/institutional/BR/pt/our-business>. Acesso em: 11 de maio de 2019b.

WEG. Sustentabilidade. Disponível em:

$<$ https://www.weg.net/institutional/BR/pt/sustainability >. Acesso em: 11 de maio de 2019c. 


\section{Anexo}

Anexo A: Variação história do PIB brasileiro

\begin{tabular}{|c|c|c|c|c|c|c|}
\hline $\mathbf{2 0 1 0 - 2 0 1 1}$ & $\mathbf{2 0 1 1 - 2 0 1 2}$ & $\mathbf{2 0 1 2}-2013$ & $\mathbf{2 0 1 3 - 2 0 1 4}$ & $\mathbf{2 0 1 4 - 2 0 1 5}$ & $\mathbf{2 0 1 5}-\mathbf{2 0 1 6}$ & $\mathbf{2 0 1 6 - 2 0 1 7}$ \\
\hline $4,0 \%$ & $1,9 \%$ & $3,0 \%$ & $0,5 \%$ & $-3,5 \%$ & $-3,3 \%$ & $1,1 \%$ \\
\hline
\end{tabular}

Fonte: IBGE, 2019.

Anexo B: Coeficiente de correlação de Pearson - EDP

\begin{tabular}{|r|c|c|c|c|}
\hline \multicolumn{1}{|c|}{ Anos } & $\boldsymbol{\Delta} \%$ PIB & $\begin{array}{c}\boldsymbol{\Delta} \% \text { Investimento/ } \\
\text { Receita Líquida }\end{array}$ & $\begin{array}{c}\boldsymbol{\Delta} \% \text { Investimento em } \\
\text { RSE/ Receita Líquida }\end{array}$ & $\begin{array}{c}\boldsymbol{\Delta} \% \text { Investimento em } \\
\text { RSE/Investimentos }\end{array}$ \\
\hline $2010-2011$ & $4,00 \%$ & $8,70 \%$ & $5,76 \%$ & $-2,70 \%$ \\
\hline $2011-2012$ & $1,90 \%$ & $-44,83 \%$ & $12,66 \%$ & $104,22 \%$ \\
\hline $2012-2013$ & $3,00 \%$ & $85,00 \%$ & $-19,13 \%$ & $-56,29 \%$ \\
\hline $2013-2014$ & $0,50 \%$ & $-63,07 \%$ & $-31,45 \%$ & $85,63 \%$ \\
\hline $2014-2015$ & $-3,50 \%$ & $19,43 \%$ & $-38,31 \%$ & $-48,35 \%$ \\
\hline $2015-2016$ & $-3,30 \%$ & $53,63 \%$ & $432,04 \%$ & $246,31 \%$ \\
\hline $2016-2017$ & $1,10 \%$ & $-34,60 \%$ & $-39,65 \%$ & $-7,73 \%$ \\
\hline p & $-0,13$ & $-0,51$ & $-0,40$ \\
\hline
\end{tabular}

Fonte: Elaborada pela autora.

Anexo C: Coeficiente de correlação de Pearson - Fibria

\begin{tabular}{|r|c|c|c|c|}
\hline \multicolumn{1}{|c|}{ Anos } & $\boldsymbol{\Delta} \%$ PIB & $\begin{array}{c}\Delta \% \text { Investimentol } \\
\text { Receita Líquida }\end{array}$ & $\begin{array}{c}\Delta \% \text { Investimento em } \\
\text { RSE/ Receita Líquida }\end{array}$ & $\begin{array}{c}\Delta \% \text { Investimento em } \\
\text { RSE/Investimentos }\end{array}$ \\
\hline $2010-2011$ & $4,00 \%$ & $-12,28 \%$ & $92,19 \%$ & $119,09 \%$ \\
\hline $2011-2012$ & $1,90 \%$ & $-38,86 \%$ & $1,61 \%$ & $66,19 \%$ \\
\hline $2012-2013$ & $3,00 \%$ & $-38,63 \%$ & $4,33 \%$ & $69,99 \%$ \\
\hline $2013-2014$ & $0,50 \%$ & $25,09 \%$ & $8,59 \%$ & $-13,19 \%$ \\
\hline $2014-2015$ & $-3,50 \%$ & $47,44 \%$ & $-32,51 \%$ & $-54,22 \%$ \\
\hline $2015-2016$ & $-3,30 \%$ & $104,86 \%$ & $28,24 \%$ & $-37,40 \%$ \\
\hline $2016-2017$ & $1,10 \%$ & $-35,71 \%$ & $4,73 \%$ & $62,89 \%$ \\
\hline
\end{tabular}

Fonte: Elaborada pela autora. 


\section{Anexo D: Coeficiente de correlação de Pearson - Natura}

\begin{tabular}{|r|c|c|c|c|}
\hline \multicolumn{1}{|c|}{ Anos } & $\boldsymbol{\Delta} \%$ PIB & $\begin{array}{c}\boldsymbol{\Delta} \% \text { Investimentol } \\
\text { Receita Líquida }\end{array}$ & $\begin{array}{c}\boldsymbol{\Delta} \% \text { Investimento em } \\
\text { RSE/ Receita Líquida }\end{array}$ & $\begin{array}{c}\boldsymbol{\Delta} \% \text { Investimento em } \\
\text { RSE/lnvestimentos }\end{array}$ \\
\hline $2010-2011$ & $4,00 \%$ & $-1,61 \%$ & $-3,30 \%$ & $-1,72 \%$ \\
\hline $2011-2012$ & $1,90 \%$ & $1083,23 \%$ & $3,37 \%$ & $-91,26 \%$ \\
\hline $2012-2013$ & $3,00 \%$ & $4,99 \%$ & $16,06 \%$ & $10,54 \%$ \\
\hline $2013-2014$ & $0,50 \%$ & $-7,63 \%$ & $150,00 \%$ & $170,65 \%$ \\
\hline $2014-2015$ & $-3,50 \%$ & $11,34 \%$ & $-49,81 \%$ & $-54,92 \%$ \\
\hline $2015-2016$ & $-3,30 \%$ & $1,18 \%$ & $22,51 \%$ & $21,08 \%$ \\
\hline $2016-2017$ & $1,10 \%$ & $47,72 \%$ & $-8,89 \%$ & $-38,32 \%$ \\
\hline p & & $\mathbf{0 , 2 1}$ & $\mathbf{0 , 1 3}$ & $\mathbf{0 , 0 1}$ \\
\hline
\end{tabular}

Fonte: Elaborada pela autora.

\section{Anexo E: Coeficiente de correlação de Pearson - Engie}

\begin{tabular}{|r|c|c|c|c|}
\hline \multicolumn{1}{|c|}{ Anos } & $\boldsymbol{\Delta} \% \mathrm{PIB}$ & $\begin{array}{c}\boldsymbol{\Delta} \% \text { Investimento/ } \\
\text { Receita Líquida }\end{array}$ & $\begin{array}{c}\boldsymbol{\Delta} \% \text { Investimento em } \\
\mathbf{R S E} / \text { Receita Líquida }\end{array}$ & $\begin{array}{c}\boldsymbol{\Delta} \% \text { Investimento em } \\
\text { RSE/lnvestimentos }\end{array}$ \\
\hline $2010-2011$ & $4,00 \%$ & $-68,75 \%$ & $64,15 \%$ & $425,26 \%$ \\
\hline $2011-2012$ & $1,90 \%$ & $-18,28 \%$ & $-29,89 \%$ & $-14,20 \%$ \\
\hline $2012-2013$ & $3,00 \%$ & $46,08 \%$ & $-14,45 \%$ & $-41,44 \%$ \\
\hline $2013-2014$ & $0,50 \%$ & $-8,77 \%$ & $-0,95 \%$ & $8,57 \%$ \\
\hline $2014-2015$ & $-3,50 \%$ & $28,13 \%$ & $-20,19 \%$ & $-37,71 \%$ \\
\hline $2015-2016$ & $-3,30 \%$ & $69,58 \%$ & $-10,82 \%$ & $-47,41 \%$ \\
\hline $2016-2017$ & $1,10 \%$ & $118,26 \%$ & $-14,28 \%$ & $-60,72 \%$ \\
\hline p & & $-0,43$ & 0,48 & $\mathbf{0 , 5 4}$ \\
\hline
\end{tabular}

Fonte: Elaborada pela autora.

\section{Anexo F: Coeficiente de correlação de Pearson - Fleury}

\begin{tabular}{|r|c|c|c|c|}
\hline \multicolumn{1}{|c|}{ Anos } & $\boldsymbol{\Delta} \%$ PIB & $\begin{array}{c}\boldsymbol{\Delta} \% \text { Investimento/ } \\
\text { Receita Líquida }\end{array}$ & $\begin{array}{c}\boldsymbol{\Delta} \% \text { Investimento em } \\
\text { RSE/ Receita Líquida }\end{array}$ & $\begin{array}{c}\boldsymbol{\Delta} \% \text { Investimento em } \\
\text { RSE/lnvestimentos }\end{array}$ \\
\hline $2010-2011$ & $4,00 \%$ & $385,78 \%$ & $-36,93 \%$ & $-87,02 \%$ \\
\hline $2011-2012$ & $1,90 \%$ & $-58,86 \%$ & $-15,37 \%$ & $105,70 \%$ \\
\hline $2012-2013$ & $3,00 \%$ & $-59,61 \%$ & $16,54 \%$ & $188,51 \%$ \\
\hline $2013-2014$ & $0,50 \%$ & $-27,59 \%$ & $-45,17 \%$ & $-24,29 \%$ \\
\hline $2014-2015$ & $-3,50 \%$ & $8,30 \%$ & $53,83 \%$ & $42,04 \%$ \\
\hline $2015-2016$ & $-3,30 \%$ & $62,01 \%$ & $-68,97 \%$ & $-80,85 \%$ \\
\hline $2016-2017$ & $1,10 \%$ & $88,71 \%$ & $173,33 \%$ & $44,84 \%$ \\
\hline P & & $\mathbf{0 , 3 3}$ & $\mathbf{0 , 0 3}$ & $\mathbf{0 , 2 7}$ \\
\hline
\end{tabular}

Fonte: Elaborada pela autora. 
Anexo G: Coeficiente de correlação de Pearson - Telefônica

\begin{tabular}{|r|c|c|c|c|}
\hline \multicolumn{1}{|c|}{ Anos } & $\boldsymbol{\Delta} \%$ PIB & $\begin{array}{c}\boldsymbol{\Delta} \% \text { Investimentol } \\
\text { Receita Líquida }\end{array}$ & $\begin{array}{c}\boldsymbol{\Delta} \% \text { Investimento em } \\
\text { RSE/ Receita Líquida }\end{array}$ & $\begin{array}{c}\boldsymbol{\Delta} \% \text { Investimento em } \\
\text { RSE/lnvestimentos }\end{array}$ \\
\hline $2010-2011$ & $4,00 \%$ & $24,37 \%$ & $-22,16 \%$ & $-37,42 \%$ \\
\hline $2011-2012$ & $1,90 \%$ & $-14,33 \%$ & $-0,38 \%$ & $16,28 \%$ \\
\hline $2012-2013$ & $3,00 \%$ & $20,38 \%$ & $-3,30 \%$ & $-19,67 \%$ \\
\hline $2013-2014$ & $0,50 \%$ & $26,21 \%$ & $1,38 \%$ & $-19,67 \%$ \\
\hline $2014-2015$ & $-3,50 \%$ & $74,31 \%$ & $-14,99 \%$ & $-51,23 \%$ \\
\hline $2015-2016$ & $-3,30 \%$ & $-52,56 \%$ & $-2,91 \%$ & $104,63 \%$ \\
\hline $2016-2017$ & $1,10 \%$ & $10,49 \%$ & $31,88 \%$ & $19,36 \%$ \\
\hline $\boldsymbol{P}$ & & $\mathbf{0 , 0 3}$ & $\mathbf{0 , 0 1}$ & $-\mathbf{0 , 3 7}$ \\
\hline
\end{tabular}

Fonte: Elaborada pela autora.

\section{Anexo H: Coeficiente de correlação de Pearson - CCR}

\begin{tabular}{|r|c|c|c|c|}
\hline \multicolumn{1}{|c|}{ Anos } & $\boldsymbol{\Delta} \%$ PIB & $\begin{array}{c}\Delta \% \text { Investimentol } \\
\text { Receita Líquida }\end{array}$ & $\begin{array}{c}\boldsymbol{\Delta} \% \text { Investimento em } \\
\text { RSE/ Receita Líquida }\end{array}$ & $\begin{array}{c}\boldsymbol{\Delta} \% \text { Investimento em } \\
\text { RSE/lnvestimentos }\end{array}$ \\
\hline $2010-2011$ & $4,00 \%$ & $-74,45 \%$ & $-3,32 \%$ & $278,44 \%$ \\
\hline $2011-2012$ & $1,90 \%$ & $64,39 \%$ & $16,22 \%$ & $-29,30 \%$ \\
\hline $2012-2013$ & $3,00 \%$ & $-20,80 \%$ & $1,58 \%$ & $28,27 \%$ \\
\hline $2013-2014$ & $0,50 \%$ & $58,88 \%$ & $-5,36 \%$ & $-40,44 \%$ \\
\hline $2014-2015$ & $-3,50 \%$ & $38,96 \%$ & $-16,40 \%$ & $-39,84 \%$ \\
\hline $2015-2016$ & $-3,30 \%$ & $-3,78 \%$ & $27,24 \%$ & $32,24 \%$ \\
\hline $2016-2017$ & $1,10 \%$ & $31,79 \%$ & $-9,23 \%$ & $-31,13 \%$ \\
\hline p & & $-0,40$ & $-0,11$ & $\mathbf{0 , 5 1}$ \\
\hline
\end{tabular}

Fonte: Elaborada pela autora.

Anexo I: Coeficiente de correlação de Pearson - WEG

\begin{tabular}{|r|c|c|c|c|}
\hline \multicolumn{1}{|c|}{ Anos } & $\boldsymbol{\Delta} \%$ PIB & $\begin{array}{c}\Delta \% \text { Investimento/ } \\
\text { Receita Líquida }\end{array}$ & $\begin{array}{c}\Delta \% \text { Investimento em } \\
\text { RSE/ Receita Líquida }\end{array}$ & $\begin{array}{c}\Delta \% \text { Investimento em } \\
\text { RSE/Investimentos }\end{array}$ \\
\hline $2010-2011$ & $4,00 \%$ & $44,96 \%$ & $-3,93 \%$ & $-33,72 \%$ \\
\hline $2011-2012$ & $1,90 \%$ & $-34,11 \%$ & $1,33 \%$ & $53,78 \%$ \\
\hline $2012-2013$ & $3,00 \%$ & $-52,19 \%$ & $28,40 \%$ & $168,59 \%$ \\
\hline $2013-2014$ & $0,50 \%$ & $340,65 \%$ & $-7,83 \%$ & $-79,08 \%$ \\
\hline $2014-2015$ & $-3,50 \%$ & $-49,53 \%$ & $-21,40 \%$ & $55,74 \%$ \\
\hline $2015-2016$ & $-3,30 \%$ & $96,67 \%$ & $-28,66 \%$ & $-63,73 \%$ \\
\hline $2016-2017$ & $1,10 \%$ & $-69,45 \%$ & $-7,73 \%$ & $202,02 \%$ \\
\hline p & $-0,09$ & $\mathbf{0 , 7 8}$ & $\mathbf{0 , 2 6}$ \\
\hline
\end{tabular}

Fonte: Elaborada pela autora. 
Anexo J: Coeficiente de correlação de Pearson - CEMIG

\begin{tabular}{|r|c|c|c|c|}
\hline \multicolumn{1}{|c|}{ Anos } & $\boldsymbol{\Delta} \%$ PIB & $\begin{array}{c}\boldsymbol{\Delta} \% \text { Investimentol } \\
\text { Receita Líquida }\end{array}$ & $\begin{array}{c}\boldsymbol{\Delta} \% \text { Investimento em } \\
\text { RSE/ Receita Líquida }\end{array}$ & $\begin{array}{c}\boldsymbol{\Delta} \% \text { Investimento em } \\
\text { RSE/lnvestimentos }\end{array}$ \\
\hline $2010-2011$ & $4,00 \%$ & $-20,53 \%$ & $-15,77 \%$ & $6,00 \%$ \\
\hline $2011-2012$ & $1,90 \%$ & $-33,33 \%$ & $32,88 \%$ & $99,31 \%$ \\
\hline $2012-2013$ & $3,00 \%$ & $-28,24 \%$ & $-12,28 \%$ & $22,24 \%$ \\
\hline $2013-2014$ & $0,50 \%$ & $85,21 \%$ & $-13,74 \%$ & $-53,43 \%$ \\
\hline $2014-2015$ & $-3,50 \%$ & $-33,13 \%$ & $-25,03 \%$ & $12,11 \%$ \\
\hline $2015-2016$ & $-3,30 \%$ & $4,44 \%$ & $-3,92 \%$ & $-8,01 \%$ \\
\hline $2016-2017$ & $1,10 \%$ & $-58,76 \%$ & $30,61 \%$ & $216,69 \%$ \\
\hline $\boldsymbol{P}$ & & $-\mathbf{0 , 1 3}$ & $\mathbf{0 , 2 3}$ & $\mathbf{0 , 2 0}$ \\
\hline
\end{tabular}

Fonte: Elaborada pela autora.

\section{Anexo K: Coeficiente de correlação de Pearson - Eletropaulo}

\begin{tabular}{|r|c|c|c|c|}
\hline \multicolumn{1}{|c|}{ Anos } & $\boldsymbol{\Delta} \%$ PIB & $\begin{array}{c}\boldsymbol{\Delta} \% \text { Investimentol } \\
\text { Receita Líquida }\end{array}$ & $\begin{array}{c}\boldsymbol{\Delta} \% \text { Investimento em } \\
\text { RSE/ Receita Líquida }\end{array}$ & $\begin{array}{c}\boldsymbol{\Delta} \% \text { Investimento em } \\
\text { RSE/lnvestimentos }\end{array}$ \\
\hline $2010-2011$ & $4,00 \%$ & $-12,48 \%$ & $-48,99 \%$ & $-41,72 \%$ \\
\hline $2011-2012$ & $1,90 \%$ & $52,65 \%$ & $45,07 \%$ & $-4,96 \%$ \\
\hline $2012-2013$ & $3,00 \%$ & $-24,58 \%$ & $3,60 \%$ & $37,36 \%$ \\
\hline $2013-2014$ & $0,50 \%$ & $-11,68 \%$ & $-32,63 \%$ & $-23,72 \%$ \\
\hline $2014-2015$ & $-3,50 \%$ & $27,53 \%$ & $-18,26 \%$ & $-35,91 \%$ \\
\hline $2015-2016$ & $-3,30 \%$ & $19,50 \%$ & $-10,49 \%$ & $-25,09 \%$ \\
\hline $2016-2017$ & $1,10 \%$ & $-29,55 \%$ & $-2,69 \%$ & $38,13 \%$ \\
\hline
\end{tabular}

Fonte: Elaborada pela autora.

Anexo L: Dados contábeis - EDP

\begin{tabular}{|c|c|c|c|c|c|c|c|c|}
\hline \multicolumn{9}{|c|}{ EDP Brasil - Consolidado (milhões R\$) } \\
\hline Conta & 2010 & 2011 & 2012 & 2013 & 2014 & 2015 & 2016 & 2017 \\
\hline Receita Líquida & $5.397,93$ & $5.705,41$ & $6.454,49$ & $7.096,49$ & $8.895,76$ & $10.260,43$ & $9.364,77$ & $12.373,38$ \\
\hline Investimentos & 924,65 & $1.062,32$ & 663,01 & $1.348,58$ & 624,30 & 860,00 & $1.205,92$ & $1.042,02$ \\
\hline $\begin{array}{l}\text { Investimento em } \\
\text { RSE }\end{array}$ & 3,96 & 4,43 & 5,65 & 5,02 & 4,31 & 3,07 & 14,90 & 11,88 \\
\hline $\begin{array}{l}\text { Investimento Social } \\
\text { externo }\end{array}$ & 3,96 & 4,43 & 5,24 & 4,77 & 3,64 & 3,07 & 14,90 & 11,88 \\
\hline $\begin{array}{l}\text { Investimento em meio } \\
\text { ambiente externo }\end{array}$ & 0,00 & 0,00 & 0,41 & 0,25 & 0,68 & 0,00 & 0,00 & 0,00 \\
\hline
\end{tabular}

Fonte: EDP Brasil, 2019a. 
Anexo M: Dados contábeis - Fibria

\begin{tabular}{|l|c|c|c|c|c|c|c|c|c|}
\hline \multicolumn{7}{|c|}{ Fibria - Consolidado (milhões R\$) } \\
\hline \multicolumn{1}{|c|}{ Conta } & 2010 & 2011 & 2012 & 2013 & 2014 & 2015 & 2016 & 2017 \\
\hline Receita Líquida & $6.283,39$ & $5.854,30$ & $6.174,37$ & $6.917,41$ & $7.083,60$ & $10.080,67$ & $9.614,82$ & $11.739,15$ \\
\hline Investimentos & $3.617,24$ & $2.956,28$ & $1.906,27$ & $1.310,75$ & $1.679,02$ & $3.522,84$ & $6.883,46$ & $5.403,44$ \\
\hline Investimento em RSE & 14,09 & 25,24 & 27,05 & 31,61 & 35,15 & 33,76 & 41,29 & 52,80 \\
\hline
\end{tabular}

Fonte: Fibria, 2019a.

Anexo N: Dados contábeis - Natura

\begin{tabular}{|c|c|c|c|c|c|c|c|c|}
\hline \multicolumn{9}{|c|}{ Natura - Consolidado (milhões R\$) } \\
\hline Contas & 2010 & 2011 & 2012 & 2013 & 2014 & 2015 & 2016 & 2017 \\
\hline Receita Líquida & $5.136,71$ & $5.591,37$ & $6.345,67$ & $7.010,31$ & $7.408,42$ & $7.899,00$ & $7.912,66$ & $9.852,71$ \\
\hline Investimentos & 323,40 & 346,37 & $4.651,18$ & $5.394,96$ & $5.266,21$ & $6.251,46$ & $6.336,21$ & $11.654,62$ \\
\hline Investimento em RSE & 110,82 & 116,65 & 136,85 & 175,46 & 463,57 & 248,09 & 304,46 & 345,42 \\
\hline Investimento nas comunidades & 8,71 & 10,04 & 12,07 & 11,17 & 8,89 & 6,58 & 10,12 & 17,94 \\
\hline Educação para benefício público & 8,40 & 10,54 & 17,30 & 21,86 & 25,49 & 30,00 & 38,20 & 35,70 \\
\hline Investimento e gastos ambientais & 69,00 & 70,90 & 73,20 & 127,70 & 406,35 & 194,58 & 246,62 & 277,80 \\
\hline Comunidades do entorno & 0,41 & 0,82 & 0,73 & 0,33 & 0,97 & 0,89 & 0,91 & 1,13 \\
\hline Apoios e patrocínios - recursos Natura & 18,70 & 18,81 & 28,08 & 9,03 & 14,89 & 10,50 & 5,43 & 10,10 \\
\hline Apoios e patrocínios - recuros incentivados & 5,60 & 5,54 & 5,47 & 5,37 & 6,99 & 5,54 & 3,18 & 2,75 \\
\hline
\end{tabular}

Fonte: Natura, 2019b.

\section{Anexo O: Dados contábeis - Engie}

\begin{tabular}{|c|c|c|c|c|c|c|c|c|}
\hline \multicolumn{9}{|c|}{ Engie - Consolidado (milhões R\$) } \\
\hline Contas & 2010 & 2011 & 2012 & 2013 & 2014 & 2015 & 2016 & 2017 \\
\hline Receita Operacional Líquida & $4.100,38$ & $4.326,95$ & $4.912,50$ & $5.568,66$ & $6.472,50$ & $6.512,04$ & $6.442,37$ & $7.009,96$ \\
\hline Investimentos & $1.094,89$ & 361,08 & 334,99 & 554,71 & 588,22 & 758,28 & $1.272,11$ & $3.021,07$ \\
\hline Investimento em RSE & 53,50 & 92,67 & 73,76 & 71,53 & 82,35 & 66,13 & 58,35 & 54,42 \\
\hline $\begin{array}{l}\text { Inv social ext - Responsabilidade Social } \\
\text { Corporativa }\end{array}$ & 13,54 & 15,29 & 17,35 & 16,28 & 18,18 & 15,32 & 26,57 & 22,28 \\
\hline Investimento ambiental & 39,96 & 77,38 & 56,41 & 55,25 & 64,17 & 50,81 & 31,78 & 32,14 \\
\hline
\end{tabular}

Fonte: Engie, 2019a. 


\section{Anexo P: Dados contábeis - Fleury}

\begin{tabular}{|l|c|c|c|c|c|c|c|c|}
\hline \multicolumn{8}{|c|}{ Fleury - Consolidado (milhões R\$) } \\
\hline \multicolumn{1}{|c|}{ Contas } & 2010 & 2011 & 2012 & 2013 & 2014 & 2015 \\
\hline Receita Líquida & 871,54 & $1.125,74$ & $1.501,78$ & $1.656,90$ & $1.678,90$ & $1.894,96$ & $2.096,11$ & $2.383,01$ \\
\hline Investimentos & 107,98 & 677,56 & 371,89 & 165,73 & 121,61 & 148,65 & 266,40 & 571,54 \\
\hline Investimento em RSE & 0,76 & 0,62 & 0,70 & 0,90 & 0,50 & 0,87 \\
\hline
\end{tabular}

Fonte: Fleury, 2019a.

\section{Anexo Q: Dados contábeis - Telefônica}

\begin{tabular}{|l|c|c|c|c|c|c|c|c|}
\hline \multicolumn{7}{|c|}{ Telefônica - Consolidado (milhões R\$) } \\
\hline \multicolumn{1}{|c|}{ Contas } & 2010 & 2011 & 2012 & 2013 & 2014 & 2015 \\
\hline Receita Operacional Líquida & $15.798,00$ & $29.129,00$ & $33.919,70$ & $34.722,00$ & $35.000,00$ & $40.287,00$ & $42.508,00$ & $43.207,00$ \\
\hline Investimentos & $2.130,02$ & $4.884,70$ & $4.873,24$ & $6.005,25$ & $7.639,72$ & $15.328,31$ & $7.673,39$ & $8.617,66$ \\
\hline Investimento em RSE & & & & & \\
\hline
\end{tabular}

Fonte: Telefônica, 2019a.

Anexo R: Dados contábeis - CCR

\begin{tabular}{|l|c|c|c|c|c|c|c|c|}
\hline \multicolumn{1}{|c|}{ Contas } & 2010 & 2011 & 2012 & 2013 & 2014 & 2015 & 2016 & 2017 \\
\hline Receita Líquida & $3.775,85$ & $4.577,57$ & $4.658,96$ & $5.206,52$ & $5.653,52$ & $6.106,85$ & $6.704,44$ & $7.537,71$ \\
\hline Investimentos & $2.237,47$ & 692,96 & $1.159,41$ & $1.026,15$ & $1.770,37$ & $2.657,29$ & $2.807,06$ & $4.159,13$ \\
\hline Investimento em RSE & 17,87 & 20,94 & 24,77 & 28,12 & 28,90 & 26,10 & 36,45 & 37,20 \\
\hline
\end{tabular}

Fonte: CCR, 2019a.

Anexo S: Dados contábeis - WEG

\begin{tabular}{|c|c|c|c|c|c|c|c|c|}
\hline \multicolumn{9}{|c|}{ WEG - Consolidado (milhões R\$) } \\
\hline Contas & 2010 & 2011 & 2012 & 2013 & 2014 & 2015 & 2016 & 2017 \\
\hline Receita Operacional Líquida & $4.391,97$ & $5.189,41$ & $6.173,90$ & $6.828,90$ & $7.840,80$ & $9.760,30$ & $9.367,00$ & $9.523,80$ \\
\hline Investimentos & 411,38 & 704,60 & 552,36 & 292,08 & $1.477,74$ & 928,40 & $1.752,30$ & 544,30 \\
\hline Investimento em RSE & 11,48 & 13,04 & 15,72 & 22,32 & 23,62 & 23,11 & 15,82 & 14,85 \\
\hline Investimento em Responsabilidade Social & 8,00 & 8,33 & 9,54 & 12,43 & 12,50 & 11,90 & 9,17 & 8,40 \\
\hline Investimento Ambiental & 3,49 & 4,71 & 6,17 & 9,89 & 11,12 & 11,21 & 6,66 & 6,45 \\
\hline
\end{tabular}

Fonte: WEG, 2019a. 
Anexo T: Dados contábeis - CEMIG

\begin{tabular}{|c|c|c|c|c|c|c|c|c|}
\hline \multicolumn{9}{|c|}{ CEMIG - Consolidado (milhões R\$) } \\
\hline Contas & 2010 & 2011 & 2012 & 2013 & 2014 & 2015 & 2016 & 2017 \\
\hline Receita Líquida & $13.846,93$ & $15.748,72$ & $14.137,36$ & $14.627,28$ & $19.539,58$ & $21.292,21$ & $18.772,66$ & $21.711,69$ \\
\hline Investimentos & $4.444,31$ & $4.016,72$ & $2.404,03$ & $1.784,95$ & $4.416,09$ & $3.217,79$ & $2.962,97$ & $1.413,38$ \\
\hline Investimento em RSE & 132,70 & 127,13 & 151,65 & 137,63 & 158,59 & 129,55 & 109,74 & 165,78 \\
\hline Investimento em Responsabilidade Social & 78,40 & 73,73 & 92,25 & 83,23 & 105,79 & 75,75 & 57,64 & 128,28 \\
\hline Investimento ambiental & 54,30 & 53,40 & 59,40 & 54,40 & 52,80 & 53,80 & 52,10 & 37,50 \\
\hline
\end{tabular}

Fonte: CEMIG, 2019a.

Anexo U: Dados contábeis - Eletropaulo

\begin{tabular}{|l|c|c|c|c|c|c|c|c|}
\hline \multicolumn{7}{|c|}{ Eletropaulo (Enel) - Consolidado (milhões R\$) } \\
\hline \multicolumn{1}{|c|}{ Contas } & 2010 & 2011 & 2012 & 2013 & 2014 & 2015 \\
\hline Receita Líquida & $9.697,16$ & $9.835,60$ & $9.959,20$ & $9.012,20$ & $10.596,60$ & $13.667,40$ & $11.659,90$ & $13.168,50$ \\
\hline Investimento & $6.332,11$ & $5.621,16$ & $8.688,47$ & $5.930,05$ & $6.157,85$ & $10.128,98$ & $10.326,28$ & $8.215,90$ \\
\hline
\end{tabular}

Fonte: Enel, 2019b,c. 